\title{
CLUSTER OBSERVES THE HIGH-ALTITUDE CUSP REGION
}

\author{
B. LAVRAUD ${ }^{1}$, H. RÈME ${ }^{1}$, M. W. DUNLOP ${ }^{2}$, J.-M. BOSQUED ${ }^{1}$, \\ I. DANDOURAS ${ }^{1}$, J.-A. SAUVAUD ${ }^{1}$, A. KEILING ${ }^{1}$, T. D. PHAN ${ }^{3}$, \\ R. LUNDIN ${ }^{4}$, P. J. CARGILL ${ }^{5}$, C. P. ESCOUBET 6 , C. W. CARLSON ${ }^{3}$, \\ J. P. McFADDEN ${ }^{3}$, G. K. PARKS ${ }^{3}$, E. MOEBIUS ${ }^{7}$, L. M. KISTLER ${ }^{7}$, \\ E. AMATA ${ }^{8}$, M. -B. BAVASSANO-CATTANEO ${ }^{8}$, A. KORTH ${ }^{9}$, \\ B. KLECKER ${ }^{10}$ and A. BALOGH ${ }^{5}$ \\ ${ }^{1}$ Centre d'Etude Spatiale des Rayonnements, 9 ave Colonel Roche, 31028, \\ Toulouse, cedex 4, France \\ E-mail:lavraud@lanl.gov; \\ ${ }^{2}$ Rutherford Appleton Laboratory, Chilton, Didcot, Oxon, OX11 0QXUK, UK; \\ ${ }^{3}$ Space Science Laboratory, UC Berkeley, CA 94530, USA; \\ ${ }^{4}$ Swedish Institute of Space Physics, Box 812 SE-981 28, Kiruna, Sweden; \\ ${ }^{5}$ Imperial College, Exhibition Road, London, $S W 72 A Z, U K$; \\ ${ }^{6}$ ESA/ESTEC RSSD, Keplerlaan 1, 2200 AG, Noordwijk, the Netherlands; \\ ${ }^{7}$ University of New Hampshire, Durham, NH 03824, USA; \\ ${ }^{8}$ Instituto di Fisica dello Spazio Interplanetario, Via del Fosso del Cavaliere, 00133, Roma, Italy; \\ ${ }^{9}$ Max-Planck-Institut Fur Aeronomie, Max-Planck-Str. 2, 37191, Katlenburg-Lindau, Germany; \\ ${ }^{10}$ Max-Planck-Institut Fur Extraterrestrische Physik, Postfach 1312, 85741, Garching, Germany
}

(Received 1 January 2003; Accepted 30 April 2004)

\begin{abstract}
This paper gives an overview of Cluster observations in the high-altitude cusp region of the magnetosphere. The low and mid-altitude cusps have been extensively studied previously with a number of low-altitude satellites, but only little is known about the distant part of the magnetospheric cusps. During the spring-time, the trajectory of the Cluster fleet is well placed for dayside, high-altitude magnetosphere investigations due to its highly eccentric polar orbit. Wide coverage of the region has resulted and, depending on the magnetic dipole tilt and the solar wind conditions, the spacecraft are susceptible to encounter: the plasma mantle, the high-altitude cusp, the dayside magnetosphere (i.e. dayside plasma sheet) and the distant exterior cusp diamagnetic cavity. The spacecraft either exit into the magnetosheath through the dayside magnetopause or through the exterior cusp-magnetosheath interface. This paper is based on Cluster observations made during three high-altitude passes. These were chosen because they occurred during different solar wind conditions and different interspacecraft separations. In addition, the dynamic nature of the cusp allowed all the aforementioned regions to be sampled with different order, duration and characteristics. The analysis deals with observations of: (1) both spatial and temporal structures at high-altitudes in the cusp and plasma mantle, (2) signatures of possible steady reconnection, flux transfer events (FTE) and plasma transfer events (PTE), (3) intermittent cold $(<100 \mathrm{eV})$ plasma acceleration associated with both plasma penetration and boundary motions, (4) energetic ions (5-40 keV) in the exterior cusp diamagnetic cavity and (5) the global structure of the exterior cusp and its direct interface with the magnetosheath. The analysis is primarily focused on ion and magnetic field measurements. By use of these recent multi-spacecraft Cluster
\end{abstract}


observations we illustrate the current topics under debate pertaining to the solar wind-magnetosphere interaction, for which this region is known to be of major importance.

Keywords: cusp, boundary layer, magnetopause, plasma acceleration

Abbreviations: DMSP - Defense Meterological Satellite Program; GSE - Geocentric Solar Ecliptic; GSM - Geocentric Solar Magnetic; HEOS - Highly Eccentric Orbiting Satellite; ACE Advanced Composition Explorer; IMF - Interplanetary Magnetic Field; MLT - Magnetic Local Time; TD - Tangential Discontinuity; RD - Rotational Discontinuity; MVA - Minimum Variance Analysis; UT - Universal Time; FGM - Fluxgate Magnetometer; FTE - Flux Transfer Event

\section{Introduction}

The magnetospheric cusps are known to be the location of magnetosheath plasma and momentum entry into the magnetosphere (Frank, 1971; Heikkila and Winningham, 1971). These regions were early evidenced in the model of Chapman and Ferraro (1931). A large number of low-altitude polar orbiting satellites have since allowed their precise characterization in terms of plasma properties and global motional behavior. The cusp plasma is made of low energy ions and electrons of magnetosheath origin (Newell and Meng, 1988). It is located near magnetic noon and extends $1-2^{\circ}$ in latitude and 1-2 $\mathrm{h}$ in local time. Early statistics from the DMSP satellites have shown it moves equatorward (poleward) in response to solar wind pressure increase (decrease), as a result of its global expansion (Newell and Meng, 1994; Yamauchi et al. 1996). For southward (northward) IMF orientation it moves equatorward (poleward) and for dawnward (duskward) IMF orientations it is displaced towards dawn (dusk) (Newell et al., 1989). Depending on these conditions the cusp region can be found in the range $\left(73^{\circ}-80^{\circ}\right)$ in magnetic latitude and $(10: 30-13: 30)$ in MLT. Surrounding the cusp, the cleft is a broader region, characterized by substantially lower magnetosheath ion fluxes, that probably maps to the low latitude boundary layers (LLBL) at higher altitudes (Newell and Meng, 1988).

The ions entering the cusp are submitted to a large-scale convection electric field. It kinetically results in large-scale "velocity filter" effect and energy-time dispersion features (Reiff et al., 1977). The plasma mantle, at the poleward edge of the cusp, constitutes the tail of the dispersed cusp. It therefore contains mainly tailward up-flowing plasma. The large-scale dispersed cusp often contains smaller scale structures. Such structures appear as purely time dependent when observed isolated in the surrounding of the cusp (Carlson and Torbert, 1980). Transient structures were also reported in the cusp boundary layers at the dayside magnetosphere. Because of their short duration, such transients are characterized 
by pitch angle dispersion (Woch and Lundin, 1992). Under strongly northward IMF, reversed large-scale convection is often measured in the cusp and similar short-lived injections may be observed within the global structure of the cusp. Because the pitch angle and energy time dispersions of these short transients are not reversed, while the convection is reversed, it was concluded that they are purely time dependent (Vontrat-Reberac et al., 2003). Ground based observations have permitted the corroboration of such observations (Lockwood et al., 2001a). Also, Escoubet et al. (1992) have reported "staircase ion signatures" within the low-altitude cusp structure, which correspond to the "cusp ion steps" reported by Lockwood and Smith (1992). These were interpreted in terms of time varying magnetosheath plasma injection and modeling of these features has reinforced this interpretation (Lockwood and Davis, 1995). Recent observations, however, have also highlighted the plausible spatial nature of such structures (Ohtani et al., 1995; Trattner et al., 1999, 2003).

Low and mid-altitude satellites have provided major advances in the understanding of the role and characteristics of the cusp, but such spacecraft only remotely sense the solar wind interaction with the cusp which actually occurs at higher altitudes. The early evidence for the existence of a slow flow region of magnetosheath plasma outside of a probable magnetopause indentation were outlined by Paschmann et al. (1976), Vasyliunas et al. (1977) and Haerendel et al. (1978), using the HEOS-2 data. While Vasyliunas (1977) referred to it as the "exterior cusp", Paschmann et al. (1976) and Haerendel et al. (1978) proposed the existence of a "stagnation region", and of an adjacent "entry layer", which could permit plasma and momentum entry into the magnetosphere through Eddy diffusion at their boundary (see also Haerendel (1978)). Their cusp picture was therefore close to an aerodynamic view, and the characteristics of the "stagnation region" compared with those inferred from the model of Spreiter and Summers (1967) for this high-altitude region. Although the term "stagnant" is often used in the literature since these early studies, plasma stagnation is qualitatively not obvious to occur in such a dynamic region, as noticed by Vasyliunas (1995).

Only recently, the Interball spacecraft (Fedorov et al., 2000; Merka et al., 2000) and the Polar spacecraft (Fuselier et al., 2000; Russell, 2000) observed the high-altitude regions of the dayside magnetosphere with high data sampling rates. The Interball spacecraft predominantly passed at very high latitudes and altitudes in the cusp and plasma mantle region but did not sample the most central part of the exterior cusp. On the other hand, the Polar spacecraft has an apogee of 9 Re (towards the cusp) and only rarely had access to the magnetosheath. Thus it did not permit extensive study of the very distant exterior cusp and its interface with the magnetosheath. 
The cusp magnetic topology was recently shown to be compatible with expectations from steady reconnection, consistent both with anti-parallel and component merging (Fedorov et al., 2000; Fuselier et al., 2000; Russell et al., 2000; Onsager et al., 2001). However, concepts involving gas dynamics (Haerendel et al., 1978; Haerendel, 1978), kinetic effects (Lemaire and Roth, 1977; Lundin et al., 2003) or waves and turbulence (Kuznetsova and Zelenyi, 1990; Belmont and Rezeau, 2001) may need be taken into account to explain the cusp properties. For instance, Walters (1966) proposed early the existence of a shock at the cusp-magnetosheath interface (see also Cargill (1999) and Taylor and Cargill (2001)) while more recent studies favor its generation via merging processes (Russell et al., 2001; Onsager et al., 2001; Lavraud et al., 2002). In this paper, we define the exterior cusp as characterized by depressed magnetic field $(<30 \mathrm{nT})$ and generally low and possibly variable ion velocities, and it is thought to be (probably) part of the more global high-altitude cusp region. The exterior cusp diamagnetic cavity appears indented in accordance with a funnel shaped topology (Russell, 2000; Lavraud et al., 2002). This region is subject to interaction with the interplanetary medium through the exterior cusp-magnetosheath boundary (Lavraud et al., 2002). The existence and exact role of magnetic field merging are not yet established. The magnetopause definition and location will be addressed in this paper (Onsager et al., 2001; Russell, 2000). We present typical Cluster observations during three outbound crossings of the high-altitude cusp (19/02/2001, 04/02/ 2001 and 18/05/2001).

The paper is focused on ion and magnetic field measurements permitting a presentation of plasma and field characteristics within a location of the magnetosphere that is still poorly known. The magnetospheric cusps were indeed anticipated to be suitable key targets for Cluster investigations. The three orbits have been chosen since their combined observations cover most of the topics mentioned below in the context of the high-altitude cusp.

In this paper, we deal with observations of "stepped" cusp structures detected in the high-altitude cusp and plasma mantle. Whether they are spatial or temporal in nature is of importance in understanding their origin. We present the observations of transient small-scale phenomena that may relate to reconnection (flux transfer events (FTEs) (Russel and Elphic, 1978)) and impulsive penetration (Lemaire and Roth, 1978). The possible occurrence of cold plasma $(<100 \mathrm{eV})$ acceleration was recently examined in Cluster observations at the flank magnetopause (Sauvaud et al., 2001). We will show that such a population is also intermittently observed at the cusp boundaries. They may be linked to sporadic boundary motions or plasma penetration and the plausible source regions are still unknown (Sauvaud et al., 2001; Lundin et al., 2003). Also, the permanent presence of high-energy ion populations (from $5 \mathrm{keV}$ to $\mathrm{MeV}$ ions) within the exterior cusp diamagnetic cavity is an intriguing feature (Delcourt and Sauvaud, 1998, 1999; 
Chen and Fritz, 2001; Fritz et al., 2003; Chang et al., 2000; Trattner et al., 2001). It is of particular interest in order to understand the role of the magnetospheric cusps for high-energy particle circulation in the magnetosphere. Finally, the global exterior cusp structure and the nature of its interface with the magnetosheath (Onsager et al., 2001; Russell et al., 2001; Lavraud et al., 2002) will be discussed. It is a prime location of the solar wind-magnetosphere interaction.

\section{Instrumentation, event selection and orbit}

\subsection{Cluster instrumentation AND SOlar Wind DATA}

The high capabilities of the onboard instruments and the tetrahedral spacecraft configuration of the Cluster fleet both permit very accurate and precise determination of the physical particle and wave phenomena and small-scale dynamical analysis. The ion data used in this paper come from the Cluster Ion Spectrometry (CIS) experiment, which is described by Rème et al. (2001). The CIS package is capable of obtaining full three-dimensional ion distribution functions with a good time resolution (down to 1 spin resolution $\sim 4 \mathrm{~s}$ ) and it also permits extensive onboard data processing. CIS is composed of two complementary sensors, the COmposition and DIstribution Function

(a)

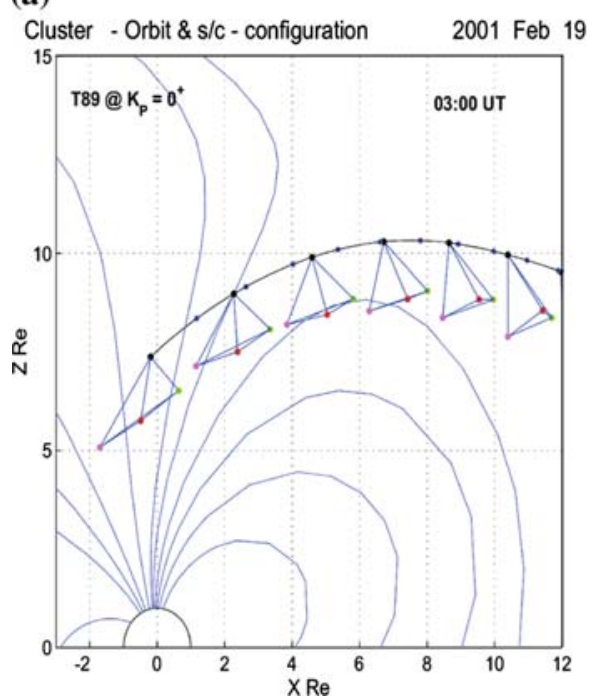

(b)

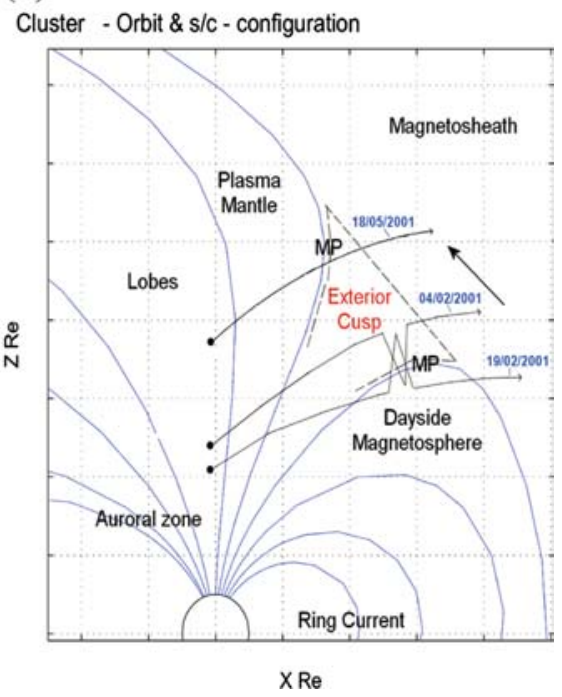

Figure 1. (a) Cluster satellites orbit on $19 / 02 / 2001$. The fleet is flying outbound from the inner magnetosphere, crossing the high-altitude cusp, the dayside magnetosphere (plasma sheet) and towards the magnetosheath. Details are given in the text of Section 2.3. (b) Schematic view of the satellites actual paths through the high-altitude dayside regions for the three events selected here. 
analyser (CODIF) sensor which handles a Time of Flight system in order to resolve ion masses, and the Hot Ion Analyser (HIA) that does not separate ion species but has a better angular resolution. The data in the present paper

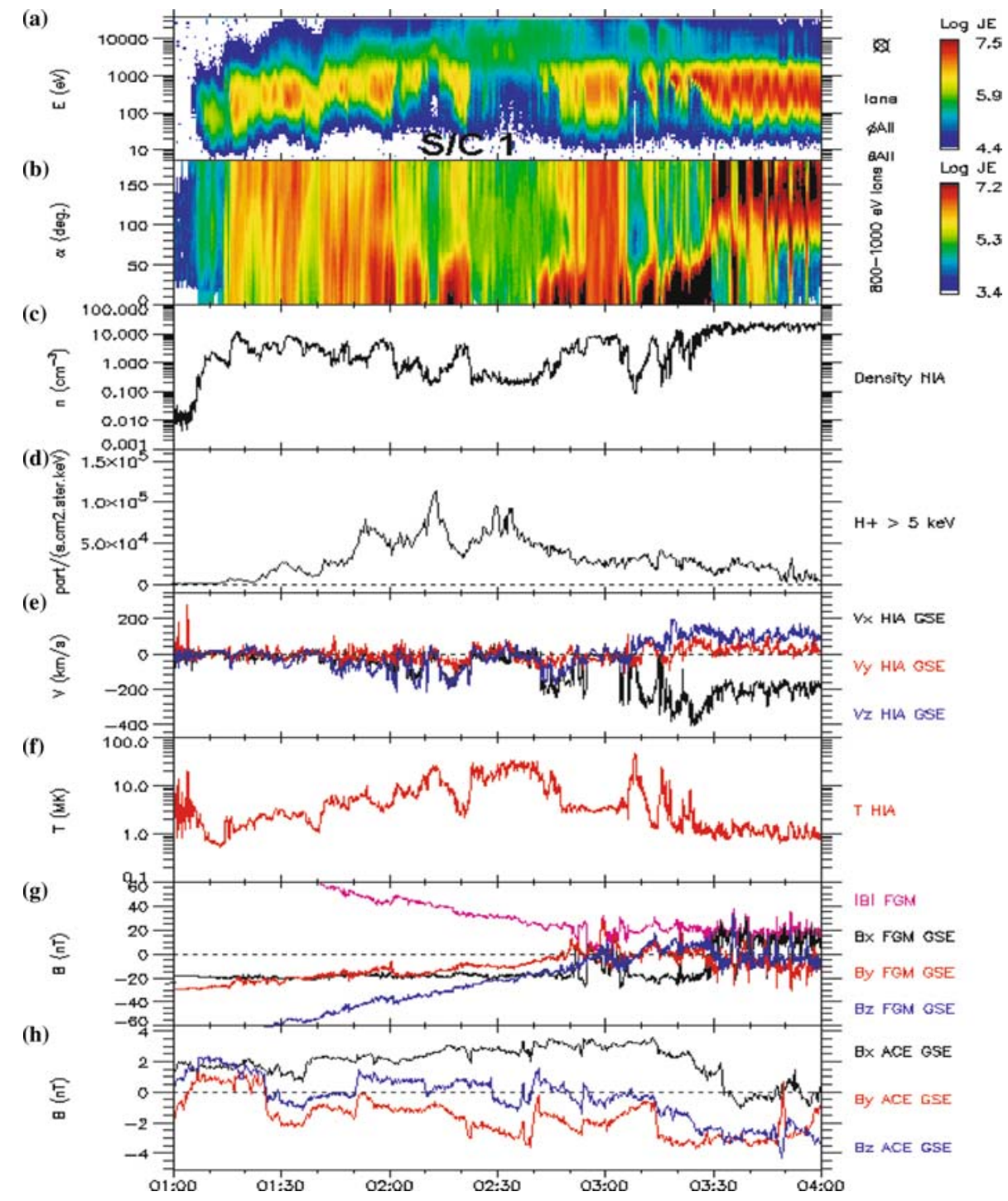

Figure 2. Overview of the combined CIS, FGM and ACE data for the 19/02/2001 event from spacecraft 1. The first spectrogram (panel a) presents HIA ion fluxes as a function of energy and time. The second spectrogram displays the pitch angle from HIA in the spacecraft frame (panel b). The ion density, the GSE velocity and the temperature of the ions from HIA are shown respectively in panels $\mathrm{c}$, e and $\mathrm{f}$. Panel $\mathrm{d}$ shows the $\mathrm{H}^{+}$fluxes from CODIF above $5 \mathrm{keV}$. Panel g presents the FGM magnetic field measurements while panel $\mathrm{h}$ displays the lagged IMF from ACE, both in GSE. 
come from both instruments. The magnetic field data used was provided by the fluxgate magnetometer experiment (FGM) (Balogh et al., 2001). The instrument can produce high-time resolution $(67$ and $22.4 \mathrm{~Hz})$ data at high absolute accuracy $(<0.1 \mathrm{nT})$. The FGM data used in this study, however, are predominantly spin averaged data to match time resolution with the plasma measurements. The ACE data are used to monitor the solar wind conditions. In Figures 2, 4 and 6, the time series of IMF have been lagged to take into account the solar wind convection from the ACE location. This was performed by direct calculation from the intrinsic characteristics of the solar wind and confirmed by correlation with FGM data when the spacecraft were in the magnetosheath.
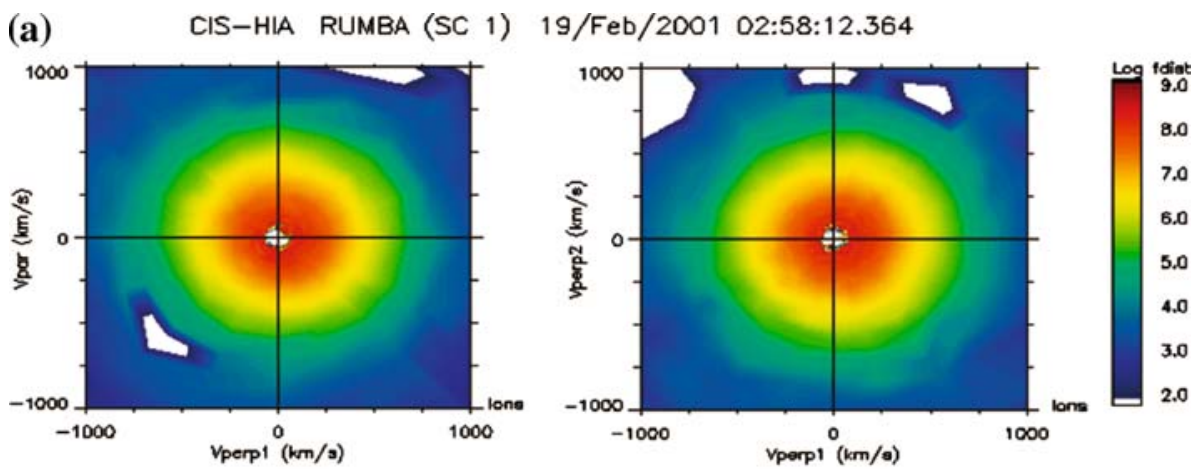

(b)

Spacecraft 1
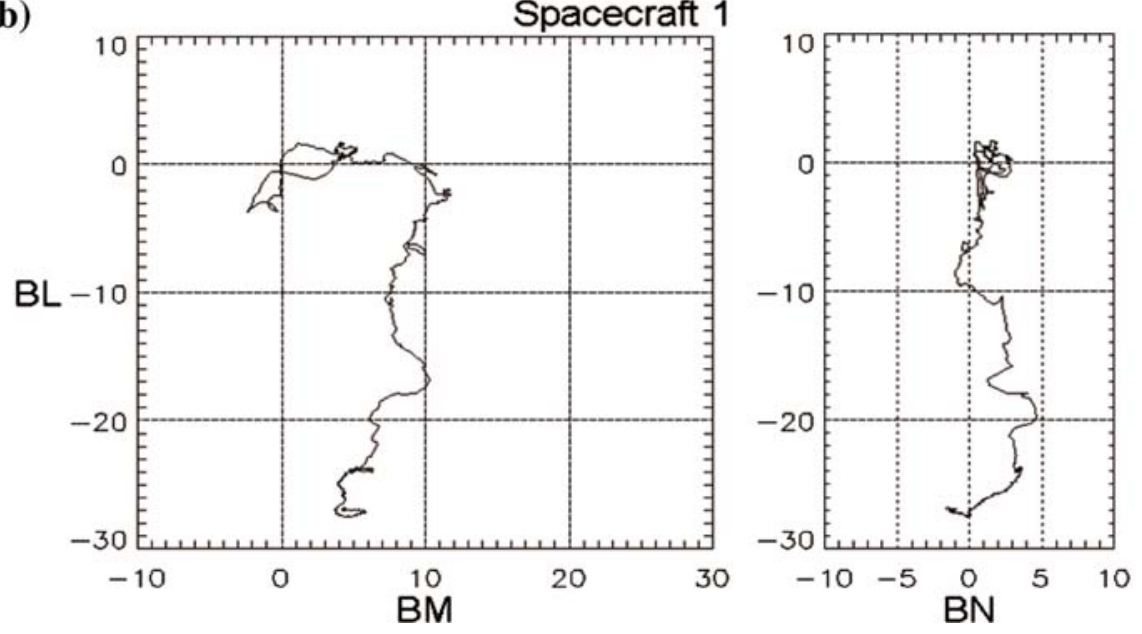

Figure 3. (a) Two-dimensional cuts of the ions distribution function in the $\left(\mathrm{V}_{\|}, \mathrm{V}_{\perp}\right)$ and $(\mathrm{V}-1$, $\mathrm{V}$-2) planes, in number flux (from HIA), and according to the magnetic field $\left(\mathrm{V}_{\|}\right)$and convection velocity $(\mathrm{V}-1)$ direction. It is sampled during the stagnant part of the exterior cusp at 02:58 UT onboard spacecraft 1. (b) Hodogram of the exterior cusp-dayside magnetosphere (boundary layer) discontinuity at $\sim 02: 55$ UT (spacecraft 1 ). The LMN coordinate system directly arises from the application of the MVA techniques. 


\subsection{Cluster event Selection}

This paper is based on the observations and analysis of three Cluster events, which occurred on 19/02/2001, 04/02/2001 and 18/05/2001. The Cluster spacecraft have an elliptical and polar orbit $\left(19.6 \times 4 R_{\mathrm{E}}\right)$. During the springtime, they are outbound from the inner magnetosphere and towards

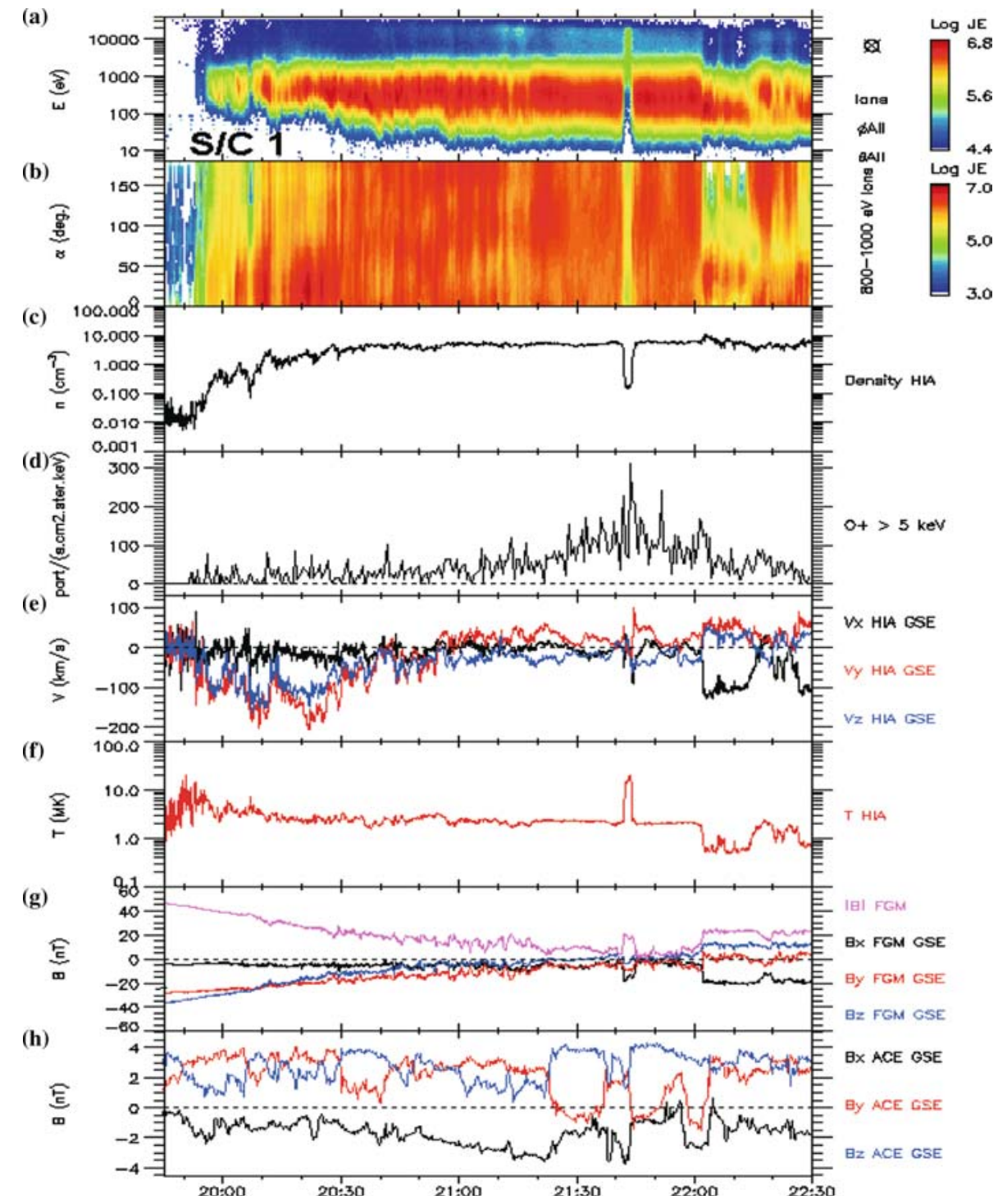

Figure 4. Overview of the combined CIS, FGM and ACE data for the 04/02/2001 event onboard spacecraft 1 . The panels are similar to Figure 4, except that panel $\mathrm{d}$ shows the $\mathrm{O}^{+}$ fluxes (instead of $\mathrm{H}^{+}$) from CODIF above $5 \mathrm{keV}$. 
the sun in the northern hemisphere. They pass through the northern lobe, plasma mantle, cusp (exterior cusp), or dayside closed magnetosphere (i.e. dayside plasma sheet) and the magnetosheath. Primarily depending on the magnetic dipole tilt angle, the solar wind conditions and the cusp global dynamics, the Cluster spacecraft are susceptible to sample these various regions with different orders and durations during similar paths on successive orbits. The 19/02/2001 and 04/02/2001 events exhibited the crossing of the exterior cusp region and its surrounding boundaries in such different ways (see later). The former event occurred under IMF $B_{z} \geq 0 \mathrm{nT}$ ) while the latter occurred under northward IMF. During these two events the inter-spacecraft separation was $\sim 600 \mathrm{~km}$. Such a configuration allows Cluster to resolve the boundary dynamics with unprecedented accuracy (Dunlop et al., this issue).
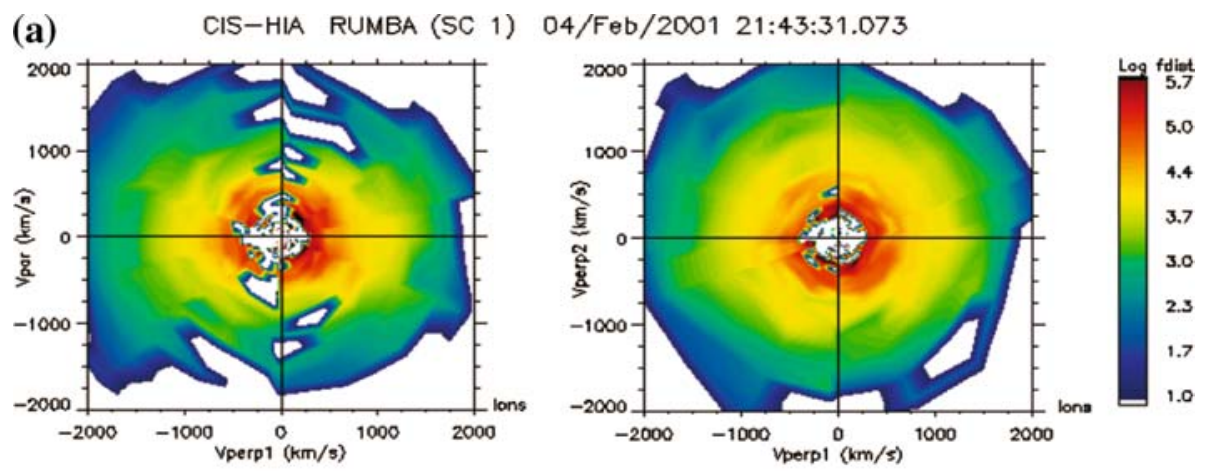

(b)
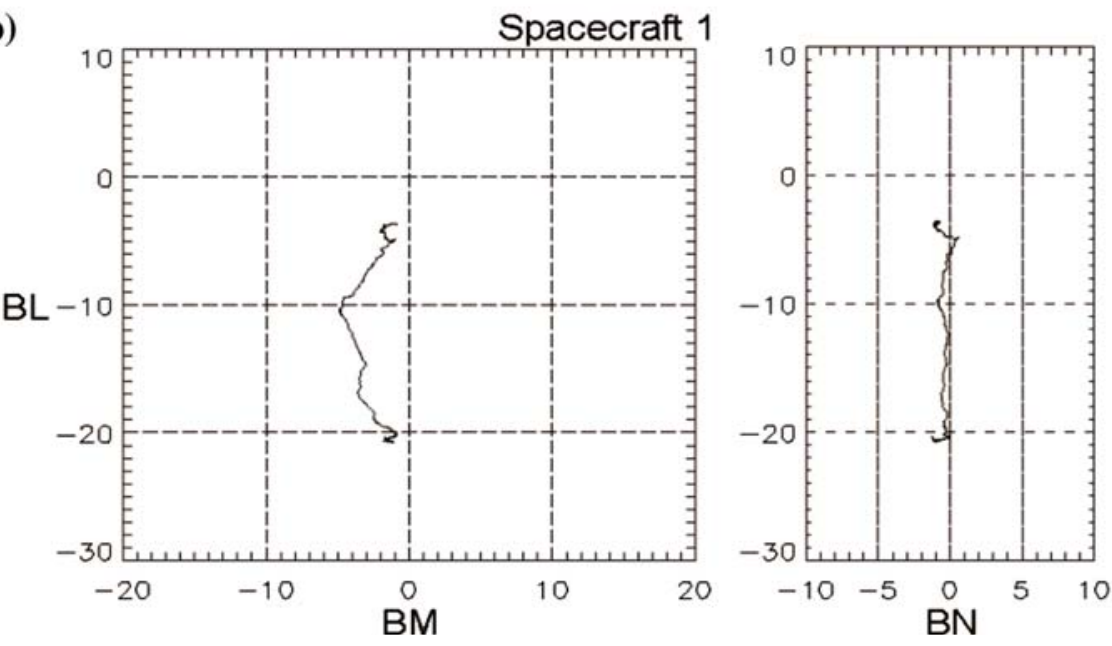

Figure 5. (a) Similar distribution functions as in Figure 3a, but the axes are extended to $2000 \mathrm{~km} / \mathrm{s}$. It is sampled in the trapped region of the dayside plasma sheet at 21:43 UT onboard spacecraft 1. (b) Similar hodogram to that of Figure $3 \mathrm{~b}$, from spacecraft 1 data at $\sim 21: 41$ UT. 
During the whole Cluster mission, this distance is changed once or twice a year depending on the anticipated scientific objectives. On 18/05/2001 the Cluster fleet mainly crossed the high-altitude plasma mantle region before
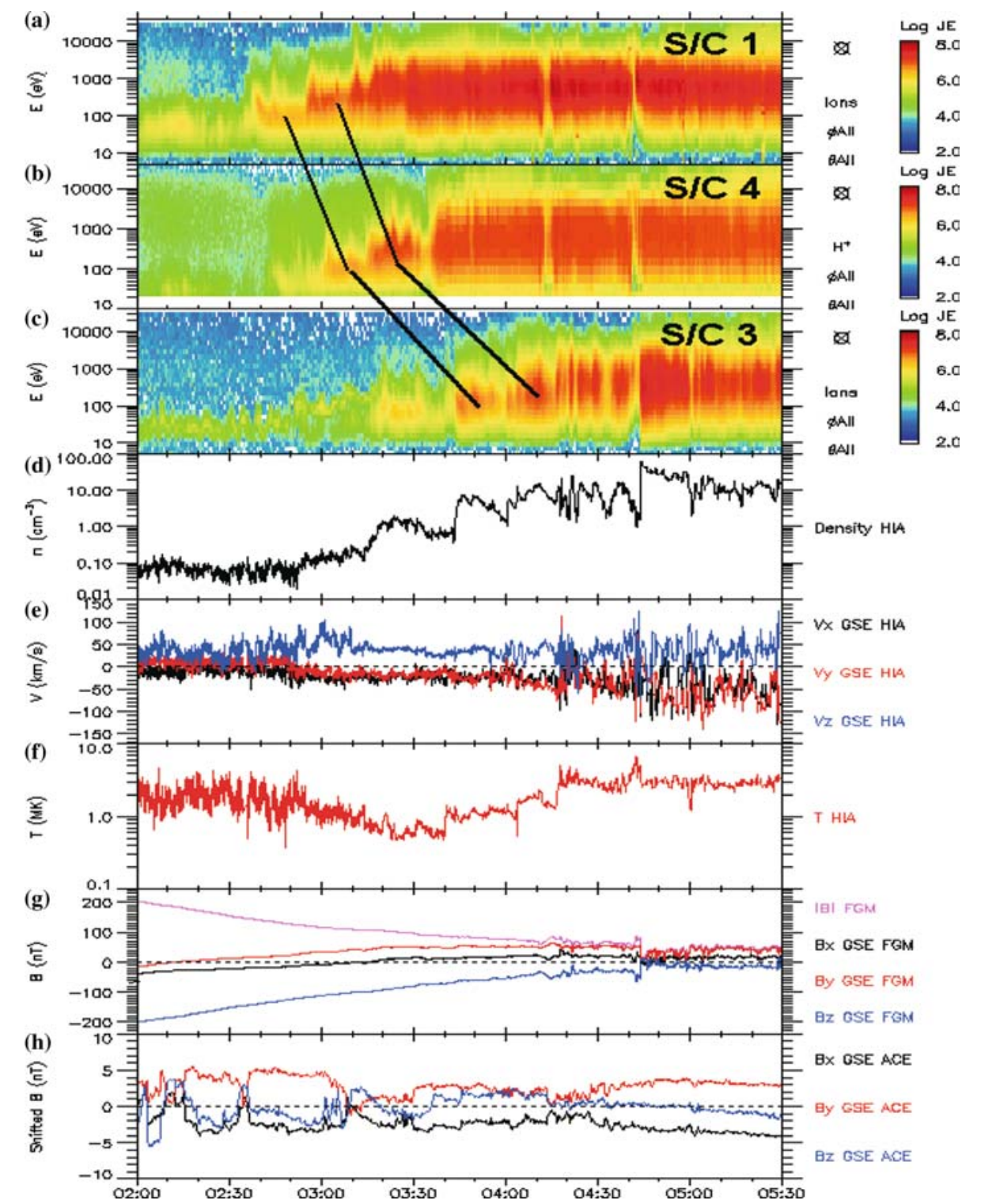

Figure 6. Overview of the combined CIS, FGM and ACE data for the 18/05/2001 event. The first panel is the spectrogram from HIA (all ions) onboard spacecraft 1 , panel $b$ is that of CODIF $\left(\mathrm{H}^{+}\right)$onboard spacecraft 4 and panel c shows HIA ions from spacecraft 3 . The ion density, the GSE velocity and the temperature of the ions from HIA onboard spacecraft 3 are shown respectively in panels d, e and f. Panel g presents the FGM magnetic field measurements (spacecraft 3) while panel h displays the lagged IMF from ACE, both in GSE. 
their exited into the magnetosheath. This event is used to highlight the largescale spatial and temporal structures often observed in the cusp and plasma mantle regions. The inter-spacecraft distance was large $\left(\sim 1 R_{\mathrm{E}}\right)$ during this pass which is appropriate for large-scale structures investigations.

\subsection{THE CLUSTER ORBITS}

Figure 1a shows the projection of the Cluster orbit (lying within 00:30 hrs of 12:00 MLT) in the $\mathrm{X}, \mathrm{Z}_{\mathrm{GSM}}$ plane for the segment between 00:00 UT and 10:00 UT on 19/02/2001. The hour intervals are marked as blue dots, increasing from 00:00 UT at the left-hand side. Superimposed with spacecraft 1 (black) attached to the orbit, are the shapes of the tetrahedra (scale factor of 20) for six arbitrary different times. The other spacecraft are color coded as: 2 (red), 3 (green) and 4 (magenta). The drawn field lines have been computed using the Tsyganenko (T89) model (Tsyganenko, 1989) with a Kp index of $0+$.

The exact Cluster orbit plots are not shown for the two other events. Rather, we display a schematic of the apparent satellites" path through the

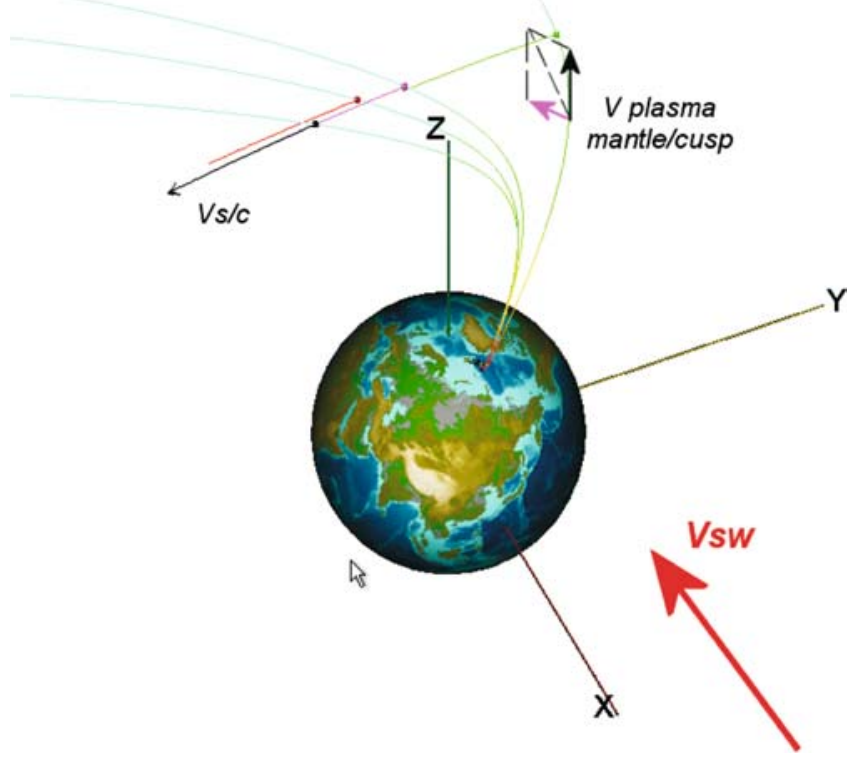

Figure 7. Perspective view of the orbit path of the four Cluster spacecraft for the $18 / 05 / 2001$ event using the Orbit Visualization Tool (OVT). Spacecraft 1 trajectory is in black and the arrow shows its direction. Similarly spacecraft 2 is in red, spacecraft 3 is in green and spacecraft 4 is in magenta. The $\mathrm{X}, \mathrm{Y}$ and $\mathrm{Z}$ axis are in GSE. The solar wind thus comes from the $\mathrm{X}$ direction. The plasma velocity orientation in the plasma mantle (see Figure 6e) is pictured through its parallel (black) and perpendicular (magenta) components, displayed as arrows. 
high-altitude cusp and its surrounding regions for the three events in Figure $1 \mathrm{~b}$. They are deduced from the observations presented in the next section. For 19/02/2001 an observed brief exit into the exterior cusp cavity is sketched as part of the trajectory. For 04/02/2001, an observed exit in opposite sense, from the exterior cusp into the dayside plasma sheet, is shown. Finally, the satellite path on 18/05/2001 is shown occurring at highaltitudes and latitudes. It must be stressed, however, that the spacecraft crossed the plasma mantle and magnetopause on the dawn edge of the exterior cusp and that the trajectory was mainly directed dawnward. Because this is a purely schematic view, the axes of Figure $1 \mathrm{~b}$ have no particular units. Note that a perspective view of the $18 / 05 / 2001$ Cluster trajectory is shown in Figure 7 (described later).

\section{Overview of three Cluster high-altitude cusp passes}

\subsection{9/02/2001: A WEAKLY SOUTHWARD IMF CUSP CROSSING}

Figure 2 shows the Cluster data from spacecraft 1 for the interval of interest on 19/02/2001. At 01:00 UT, the Cluster satellites were in the northern lobes, the ion density was very low, $\mathrm{n} \sim 0.01 \mathrm{~cm}^{-3}$ (panel c). The interval 01:05 UT to $02: 20 \mathrm{UT}$ is identified as a pass through the northern mantle and highaltitude cusp. Here, the HIA experiment measured both up and downflowing ions as seen by populations over all pitch angles (panel b). The bulk velocity was low due to these oppositely directed flows (panel e). The plasma mantle was observed first (roughly between 01:05 UT and 01:30 UT). The bulk ion velocity was characterized by a slightly positive (near zero) $\mathrm{Vz}$ component that gradually decreased down to $-200 \mathrm{~km} / \mathrm{s}$ (panel e). It indicates that more and more down-flowing particles were detected until 02:20 UT. It was also accompanied by a gradual increase in the particle mean energy. An energy-time dispersion feature is clearly observed in the spectrogram of panel a, which also reveals a stepped and saw-tooth like global pattern. The pitch angle spectrogram shows that multiple short injections occurred at small time scales. They are characterized by field aligned $\left(0^{\circ}\right.$ pitch angle) particles being detected first. Their pitch angles then increase. The particles may ultimately become anti-field aligned $\left(180^{\circ}\right)$ once they have mirrored at low-altitudes (for instance at 01:20 and 01:30 UT). Note that the pitch angles are computed in the spacecraft frame and for the energy range between 800 and $1000 \mathrm{eV}$.

A first short encounter with the dayside plasma sheet occurred at 02:10 UT, there the density decreased and the ion velocity became very low. The temperature and the high-energy proton fluxes were high (panels c, d, e and $\mathrm{f}$ ). The Cluster spacecraft appear to return to the dayside plasma sheet at 02:20 UT. The HIA measurements showed a clearly trapped high-energy (all 
above $1 \mathrm{keV}$ ) ion population at this time (distribution function not shown, a similar one is shown for the next event). Near the dayside plasma sheet-cusp boundary, the CIS instruments detected multiple transient features that appeared to contain magnetosheath like plasma. Such transients were seen at 02:30 UT in panel a, for example. They are further examined in Section 4.2.

The Cluster spacecraft thus appeared to successively cross the plasma mantle, the high-altitude cusp and the dayside plasma sheet. According to the Cluster orbits, it could have been expected that the spacecraft would then cross the dayside magnetopause. The four spacecraft appear to encounter the exterior cusp diamagnetic cavity (low field and velocity around 03:00 UT), however, and experienced a number of encounters with boundary layers at the edges of this cavity (between 02:40 and 02:55 UT for instance). The boundary layers are characterized by a mixture of populations, arising from both the magnetosheath and the dayside plasma sheet. The magnetic field shows no particular transition between the dayside plasma sheet and these boundary layers, where it thus has a typical magnetospheric orientation and strength (panel g). Sharp magnetic boundaries are delimiting these boundary layers (and subsequently the dayside plasma sheet) from the low magnetic field cavity. They were encountered at 02:55 UT on entry and 03:03 UT on exit. This diamagnetic cavity is interpreted as the exterior cusp (Russell, 2000). The magnetic field data from the 02:55 UT crossing are shown in the hodogram of Figure $3 \mathrm{~b}$. This boundary looks like a tangential discontinuity (TD) since $\mathrm{Bn}$ is $\sim 0 \mathrm{nT}$ on average during the crossing. The normal direction derived from the Minimum Variance Analysis (MVA) technique (Sonnerup and Cahill, 1967) yields $\mathbf{n}=(-0.20 ; 0.81 ; 0.54)$ in GSE. The exit at 03:03 UT gave an $\mathbf{n}=(0.39 ;-0.77 ;-0.49)$ in GSE consistent with the entry. This boundary also looks like a TD (not shown). The intermediate-to-minimum eigenvalue ratio is around 2.5 for both crossings, but the normals are stable to variation of the computation interval. The application of the Planar Discontinuity Analysis (Planar DA) on the magnetic field time series (Dunlop et al., 1997) gives average normal speeds of $\sim 30 \mathrm{~km} / \mathrm{s}$ for the two crossings. Moreover, the consistency of the normal derived from MVA with the delays in the Cluster four spacecraft time series is well established (see for example Dunlop et al., this issue). The multi-spacecraft time series data reveal a nested feature (not shown), suggesting the spacecraft have gone back and forth into a region rather than that they have sampled a transient structure passing by. Inside the exterior cusp (diamagnetic cavity) both the magnetic field and the plasma flow were very low as compared to the surrounding boundary layers and dayside plasma sheet regions (panels $\mathrm{d}$ and f). The plasma can even be shown to be quasi-isotropic and stagnant as seen in the pitch angle spectrogram (panel b). This is further revealed by the distribution function displayed in Figure 3a. 
Panel d displays the $\mathrm{H}^{+}$fluxes from CODIF above $5 \mathrm{keV}$. At the beginning of the interval, no flux was observed in the lobes, but gradually increased in the high-altitude cusp. The fluxes increased further in the dayside plasma sheet (where only this high-energy component is observed). Detection of large fluxes first occurred at 02:10 UT during the first short encounter and again after 02:20 UT. The fluxes gradually decreased throughout the boundary layers and the exterior cusp cavity, from 02:40 to 02:55 UT. The presence of this high-energy component is also seen above $5 \mathrm{keV}$ in the spectrogram of panel a. The fluxes consistently appear lower in the exterior cusp and boundary layers than in the dayside plasma sheet. The fluxes in panel d keep low after 03:00 UT and finally gradually decayed when the spacecraft were in the magnetosheath. The fluxes nearly vanish at 03:50 UT. Note that the $\mathrm{O}^{+}$fluxes above $5 \mathrm{keV}$ show a similar behavior, but with lower fluxes (not shown).

The dayside magnetopause encounter occurred at $\sim 03: 30$ UT. This magnetopause crossing was typical in the sense that the spacecraft did not exit into the magnetosheath directly from the exterior cusp (Lavraud et al., 2002). For this boundary, MVA gives a normal $\mathbf{n}=(0.41 ; 0.45 ; 0.78)$. However, the eigenvalue ratio is quite low $(\sim 2)$ and the possible TD or RD nature can not be inferred from the hodogram signature (not shown). In line with this, the planar DA gives not very consistent results. Applying a geometrical method as in Harvey (1998) yields a normal $\mathbf{n}=(0.60 ; 0.78 ; 0.17)$ and a rough inward normal speed of $\sim 65 \mathrm{~km} / \mathrm{s}$, for this boundary. In the magnetosheath, the ion density was $\sim 20 \mathrm{~cm}^{-3}$ and the measured FGM magnetic field pointed mainly sunward and southward, as can be seen in panel g. For that time (03:10 UT) the ACE spacecraft had monitored a mainly southward IMF (panel h). The large Bx component in FGM data at that time may arise from draping effect. Some transient variations of the magnetic field were however observed during this magnetosheath period. They were correlated with somewhat enhanced flows (they are discussed in section 4.2). From 01:30 to 03:10 UT the $\mathrm{B}_{z}$ component of the IMF was varying around zero. However, the $\mathrm{Bx}$ component was large and positive so that the expected magnetosheath field at the magnetopause should have an anti-parallel orientation with respect to the dayside magnetospheric field. From then on, the IMF was clearly southward.

\subsection{4/02/2001: A NORTHWARD IMF CUSP CROSSING}

This event was already discussed by Lavraud et al. (2002). We review however the Cluster observations to the extent needed for the present paper. The overview of Cluster data for this event is displayed in Figure 4 for spacecraft 1. Until 19:55 UT the Cluster fleet was in the northern lobes, where the density is very low, after which they entered the high-altitude cusp. 
It was characterized by down-flowing magnetosheath like plasma. On a large-scale, the cusp looked different from the previous event. First, no plasma mantle was observed at all on the poleward side of this cusp traversal (panels a and c). High energy, hot magnetosheath like plasma was encountered first with large downward velocities on the polewardmost field lines. In contrast also, the mean energy of the ions was gradually decreasing while there was a clear gradual change in ion velocity and temperature from 19:55 UT to 21:20 UT roughly (panels a, e and f). This behavior is characteristic of a reversed time dispersion that is consistent with the sunward plasma convection (not shown) measured in the flows. Also, on small-scales within the cusp structure (for instance just at 20:00 and 20:10 UT), short plasma injections are observed. The particles are mainly field aligned $\left(0^{\circ}\right.$ pitch angle) at first, but within few minutes the particle pitch angle evolves and more up flowing ions $\left(180^{\circ}\right.$ in pitch angle) were detected. Pitch angles are computed in the spacecraft frame for the range $(800,1000) \mathrm{eV}$.

After these cusp plasma flow signatures, instead of passing through the dayside plasma sheet as for the previous 19/02/2001 event, the spacecraft remained inside the cusp until a direct exit into the magnetosheath (apart from a very brief dayside plasma sheet encounter, discussed next). The cusp throat was filled with magnetosheath plasma, that appeared to be the more isotropic the further out the spacecraft were on their orbit path. Simultaneously, the magnetic field was continuously decreasing (from 19:55 UT until 21:20 UT). Those characteristics are displayed in the pitch angle spectrogram of panel $\mathrm{b}$ and in panel $\mathrm{g}$ for the magnetic field data. After 21:20 UT the magnetic field was constantly very low while the ion distribution functions were very isotropic. The distribution functions resembled the one shown in Figure 3a for the previous 19/02/2001 event (but not shown here). These properties led Lavraud et al. (2002) to use the descriptive term of Stagnant Exterior Cusp (SEC) for the region observed from 21:20 to 22:02 UT.

The spacecraft had a short encounter with the dayside plasma sheet at $\sim 21: 43$ UT, showing high fluxes of high-energy particles (all above $1 \mathrm{keV}$ ) and high temperatures (panels a and f). A typically trapped distribution function taken during this encounter is shown in Figure $5 \mathrm{a}$ (note that the axis scale is larger than in Figure $3 \mathrm{a}$ ). In both the aligned and anti-aligned direction, the lower phase space density of the high-energy ions (as compared to the perpendicular directions) marks the loss cone effect. The spacecraft appear to enter the dayside plasma sheet but quickly return into the exterior cusp. This back and forth motion is evidenced in the nested nature of magnetic field data time series, which opposes to a lagged nature which would characterize a convected structure (see panel b in Figure 14 introduced later). The hodogram of the first boundary encounter (arising from the MVA), between the exterior cusp and the dayside plasma sheet, is shown in Figure $5 \mathrm{~b}$ to look like a TD since the $\mathrm{Bn}$ component is particularly low 
across the boundary. It resembles the one analyzed for the previous 19/02/ 2001 event, between the exterior cusp and the dayside plasma sheet (or rather the boundary layers, see previous section). The normals derived from MVA at the entrance and exit are in good accordance with expectations from a funnel shaped cusp topology. The entry and exit have respective normal orientations $\mathbf{n}=(-0.43,0.57,0.71)$ and $\mathbf{n}=(-0.10,-0.13,0.99)$ in GSE coordinates. Both crossings show boundary normal velocities of $\sim 10 \mathrm{~km} / \mathrm{s}$ by use of the planar DA and with good time delay consistency.

The whole exterior cusp was also filled with high-energy particles $(>5 \mathrm{keV}$ ) with fluxes, however, which were lower than in the dayside plasma sheet (see panel a). This high-energy population was primarily made of $\mathrm{H}^{+}$ ions (as for the previous 19/02/2001 event), but an $\mathrm{O}^{+}$component was also detected. We display the high energy $\mathrm{O}^{+}$fluxes above $5 \mathrm{keV}$ during the whole event in panel d. It highlights that those ions were most present in the dayside plasma sheet and that the fluxes gradually decayed each side of the exterior cusp-dayside plasma sheet boundary. After 22:02 UT the spacecraft were in the magnetosheath and the fluxes decreased. The $\mathrm{H}^{+}$component above $5 \mathrm{keV}$ behaved similarly to $\mathrm{O}^{+}$during the interval (but with well higher fluxes) (not shown). Apart from the small enhancement around 22:20 UT, the fluxes of both high-energy $\mathrm{O}^{+}$and $\mathrm{H}^{+}$became very low further out in the magnetosheath.

The spacecraft exited from the exterior cusp into the magnetosheath at 22:02 UT through a very sharp discontinuity that displayed huge plasma and field parameter jumps. Lavraud et al. (2002) found it to be rotational $(\mathrm{Bn} \sim-3 \mathrm{nT})$. They showed that clear plasma inflow occurred at the boundary, which was consistent with the Bn sense. Their Walen test succeeded, indicating that the tangential stress balance at the discontinuity is apparently compatible with a RD. The boundary was also shown to be spatially stable since it was similarly sampled on all four spacecraft. Its normal, derived from MVA, was pointing outwards and upwards $\mathbf{n}=(0.65$, $0.45,0.61$ ). Planar DA revealed a normal boundary speed of $\sim 8 \mathrm{~km} / \mathrm{s}$ inwards and showed a good consistency with the four spacecraft timings. The de Hoffmann-Teller frame at the RD was found to be $(4,31,-32) \mathrm{km} / \mathrm{s}$ in GSE, thus slowly moving sunward. As can be inferred from the pitch angle spectrogram in panel $b$, the distribution functions are very isotropic from 21:20 UT until the final exit into the magnetosheath. The magnetosheath is merely convecting.

\subsection{8/05/2001: A HIGH-ALTITUDE PLASMA MANTLE AND CUSP CROSSING}

The overview of Cluster data for this event is displayed in Figure 6. While the first three panels show the spectrograms for spacecraft 1, 4 and 3, the displayed moments only come from spacecraft 3 . A perspective view of the 
Cluster orbit is shown in Figure 7 for the interval 03:00-04:00 UT. It shows that the three spacecraft (s/c1 in black, s/c3 in green and s/c4 in magenta) nearly follow each other on their orbit path, having a main dawnward direction. The arrows aim to give an idea of the plasma flow direction in the plasma mantle region and in the solar wind.

Until 03:20 UT spacecraft 3 was in the northern lobes. It then entered the plasma mantle, which was characterized by upward and tailward flowing magnetosheath like plasma (panel e in Figure 6). In the plasma mantle, the convection (perpendicular component) velocity is $\sim 20 \mathrm{~km} / \mathrm{s}$ and almost exclusively in the -X GSE direction (not shown). On all spacecraft a global increase, on large scales, of the ion mean energy is seen during the interval before each of them finally exit into the magnetosheath. This can be expected, together with the density and temperature evolution, from time of flight effect (panels $\mathrm{d}$ and $\mathrm{f}$ ). However, this dispersion feature is interrupted by several sudden energy increases that may be referred to as "steps" (Lockwood and Smith, 1992). There are two major steps that are similarly sampled, but delayed, on all three operating CIS instrument onboard spacecraft 1, 4 and 3. Their lag time between spacecraft 1 and 4 is 20 min while it is 68 min between spacecraft 1 and 3 . These coherent structures are indicated by the black lines on Figure 6. The structures are identified in terms of their highly concordant ion mean energy, spectral width and time duration on each spacecraft. Therefore they are thought to be possibly the same structures. It may be noted that sampling several, such similar steps over a long time period is rare, adding much interest to this event. Although alternate interpretations may be kept in mind, we will deal in the discussion Section 4.1 with their probable spatial nature.

The magnetopause was encountered at 04:45 UT on spacecraft 3 , as seen in the magnetic field of panel $\mathrm{g}$. The MVA derived normal is $\mathbf{n}=(0.40 ; 0.62$; 0.67 ) (hodogram not shown). The TD or RD nature is unclear. The intermediate to minimum eigenvalue ratio is quite low $(\sim 2)$ and the normal is not stable under variation of the computation interval. This means the computed normal may be wrong. Because of the large inter spacecraft separation, geometrical analysis cannot be performed for this crossing. It may already be noted that the magnetopause characteristics are not of prime importance for the analysis of this event. Nevertheless, taking into account the spacecraft location and the normal derived from MVA, it might be inferred that the spacecraft were near the high-altitude cusp indentation. But no cusp-like feature (penetrating plasma) was detected on spacecraft 3. After the magnetopause crossing, the Cluster fleet was in a perturbed magnetosheath. The velocities and the magnetic field were characteristic for the region but quite variable as seen in panel e. On spacecraft 1 (panel a) the magnetopause was encountered at 03:30 UT, and for this event an exterior cusp pass was observed for few tens of minutes before the exit into a disturbed magnetosheath. It was 
characterized by a rather turbulent region showing downward flowing ions (not shown). Spacecraft 4 (panel b) was in the plasma mantle and also entered the exterior cusp region at $\sim 03: 40$ UT. A clear plasma and magnetic boundary was observed at 04:45 UT and the spacecraft then sampled a perturbed magnetosheath (not shown). Each spacecraft thus did not sample the exterior cusp and its surrounding in the same manner, but the stepped structures that are of concern here are all detected in the plasma mantle region. At 04:45 UT, the magnetopause was crossed by spacecraft 3 , but at the same time the two other spacecraft also had a short encounter with the magnetopause, as may be observed on the spectrograms of panels a and b, while they were already in the magnetosheath. Such a transient encounter with the magnetopause also occurred before, at 04:15 UT, but only for spacecraft 1 and 4 . While plasma mantle structures were seen with a time delay, these magnetopause crossings occurred simultaneously. From the available ACE and WIND data, no clear IMF changes were correlated with these transient encounters (panel h). The solar wind pressure was high $(4 \mathrm{nPa})$ but seems to stay constant over this interval. The features of most interest here, however, are the stepped structures observed similarly on the spacecraft in the plasma mantle region, at very different times. During most of this event the ACE spacecraft monitored a low and variable IMF $\mathrm{B}_{z}$ component while a positive $\mathrm{B}_{y}$ and negative $\mathrm{B}_{x} \mathrm{IMF}$ components were dominating (panel h).

\section{Discussions}

We now discuss more specific topics that constitute the main, but nonexhaustive, current scientific debates concerning the high-altitude cusp region of the magnetosphere. We place our discussion in the context of each phenomenon that we aim to describe through these three cusp passes. We highlight the new insights coming from both the recent studies referenced herein and the additional information arising from the present analysis.

First, the present observations show that the high-altitude cusp region is filled with magnetosheath plasma of solar wind origin. Both precipitating and mirrored components are often observed. On the other hand, the dayside plasma sheet is mainly populated with ions of magnetospheric origin. Another permanent difference between the dayside plasma sheet and the cusp (and magnetosheath) is the mean energy of the ions which is of few hundreds $\mathrm{eV}$ in the cusp while ions in the dayside plasma sheet have energies of the order of $10 \mathrm{keV}$. The plasma mantle region is located tailward of the cusp. It is composed of ions originating from the cusp, that have mirrored at lowaltitude and convected tailward. Note that the plasma mantle forms a boundary layer and there also often exist boundary layer regions adjacent to the equatorward side of the cusp. They show a mixture of plasma from 
different origins and usually present typical dayside magnetospheric field orientation and strength. Such boundary layers are seen on 19/02/2001 on each side of the exterior cusp diamagnetic cavity. The processes driving their formation are still unclear.

\subsection{The SPATIAL AND TEMPORAL STRUCTURES IN THE High-ALTitUde CUSP AND MANTLE}

A great deal of knowledge on the cusp structure has come from mid and lowaltitude satellite observations, as early reported by Newell and Meng (1988), Newell et al. (1989), Woch and Lundin (1992) and Yamauchi and Lundin (1994). For instance, the large-scale energy dispersed patterns observed in the high-altitude cusp for all three events, increasing for the southward IMF on $18 / 05 / 2001$ and the weak IMF $\mathrm{B}_{z}$ event on 19/02/2001, and slightly decreasing for the $04 / 02 / 2001$ northward IMF event, are common cusp features. These dispersions are suggestive of the differential convectional flows in the region depending on the IMF orientation (Lockwood and Smith, 1992). The plasma mantle also shows the energy latitudinal dispersion for the $19 / 02 / 2001$ and $18 / 05 / 2001$. In this region the plasma bulk flow is mainly directed upward and tailward. It constitutes the natural continuation of the cusp precipitation when the cusp large-scale convection is tailward. The plasma mantle thus may not form under northward IMF conditions and possible sunward cusp convection. Its absence on 04/02/2001 is strong evidence, as first reported by Sckopke et al. (1976). Of course, the presence or absence of this region strongly depends on the steady or variable nature of the IMF and the subsequent large-scale convection in the cusp.

As explained by Lockwood and Smith (1992), the combination of pulsed reconnection events and tailward field line convection possibly induces the "Cusp Ion Step" like structure observed in the low and mid-altitude cusp region (see also Escoubet et al., 1992). When taking into account the differential plasma convection velocity and spacecraft velocity in the cusp, and when assuming purely time dependent plasma injection into the cusp, such stepped structures may appear (Lockwood and Davis, 1995). Note, however that this combined convection/velocity filter effect may equally take place by considering other injection processes. A nearly equivalent behavior is expected, but within a reversed dispersion, for steady northward IMF.

The step features appear to be composed of smaller scale events, showing pitch angle evolution from down-flowing field aligned to up-flowing anti field aligned. Such short time-pitch angle dispersions are common in the cusp region. They were presented as small-scale structures in the observation section for the 19/02/2001 and 04/02/2001 events. They display the different travel time of ions in injection events depending on their individual pitch angle. This is suggestive of the temporal nature of particle injections which 


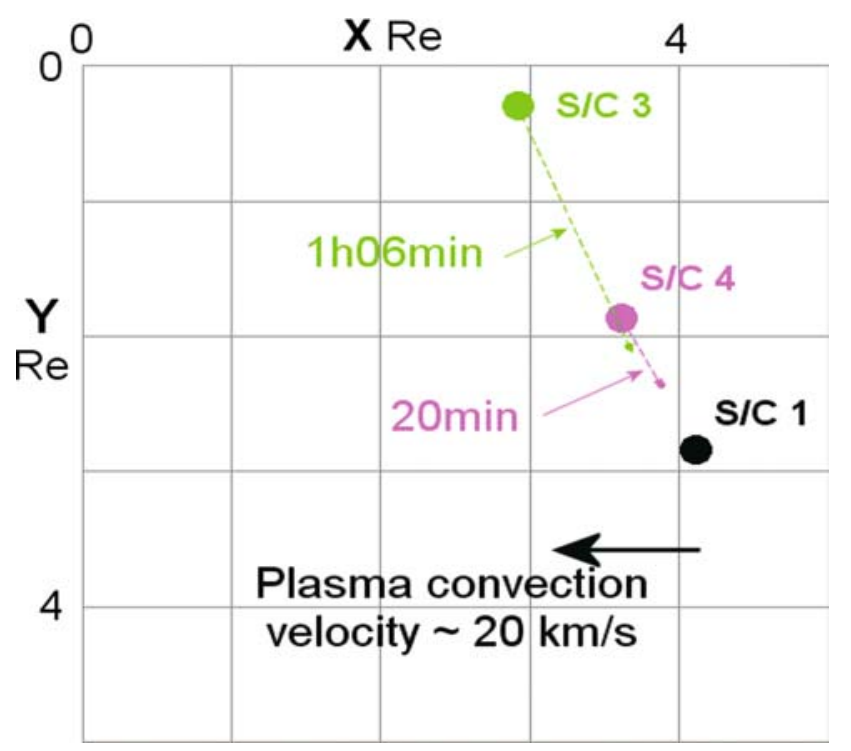

Figure 8. Schematic view showing the location of each spacecraft (filled circles) on 18/05/ 2001 at $\sim 02: 55$ UT when spacecraft 1 sampled a particular structure in the plasma mantle. The two arrows show the (respective) spacecraft spatial motion of spacecraft 3 and 4 until they sample the same structure as spacecraft 1. Rough plasma convection (perpendicular velocity) at that time is shown as a black arrow.

are ultimately mirroring at lower altitude (Reiff et al., 1977; Vontrat-Reberac et al., 2003).

The temporal variability of the cusp was also pointed out, and established, in conjunction with ground observations of poleward moving auroral forms (Lockwood et al., 2001a). Such combined signatures are of major importance in discriminating between spatial and temporal interpretations. Assuming a unique time dependence, any large-scale structure in the cusp should convect as a whole poleward (equatorward) for southward (northward) IMF. However, based on dual spacecraft measurements in the mid-altitude cusp, Trattner et al. (2002) emphasized that stepped cusp structures are sometimes sampled at the same magnetic latitudes for largely different times, suggesting a spatial nature. Those structures have been interpreted in terms of possible different plasma characteristics between adjacent convection cells as well as in terms of multiple reconnection (Newell and Meng, 1991; Trattner et al., 1999, 2002; Vontrat-Reberac et al., 2003).

The 18/05/2001 event was chosen to illustrate the possible appearance of spatial structures in the high-altitude plasma mantle region. The multi-spacecraft Cluster mission is adequate for such investigations. During the period presented in Figure 6 the inter-spacecraft separation was $\sim 1 R_{\mathrm{E}}$, in a quasi-string-of-pearl configuration. Figure 8 shows Cluster spacecraft locations (1, 3 and 4 as color-coded filled circles) at 02:55 UT (GSE), the 
time when s/c 1 detected the second step feature (second black line in Figure 6). The green and magenta arrows show the respective motions of spacecraft 3 and 4 until they sampled the same feature. The time delays are respectively 68 and $20 \mathrm{~min}$. The velocity computed from the delays and the spatial separation between each spacecraft at the sample time of this step yield a X component that is less than $1 \mathrm{~km} / \mathrm{s}$. The analysis shows a similar result for the first structure (first black line in Figure 6). This rough velocity estimate for the structures strongly differs from the $\sim 20 \mathrm{~km} / \mathrm{s}$ plasma convection velocity measured by CIS in the region, that is predominantly in -X GSE direction. The possible appearance of similar structures at the same locations after huge time delays, and under large-scale tailward convection, is thus evidenced here. At large inter-spacecraft separations, the Cluster fleet has been able to confirm the presence of apparently spatial structures in the plasma mantle at high-altitudes. The reasons for their existence are unclear and deserve further investigations.

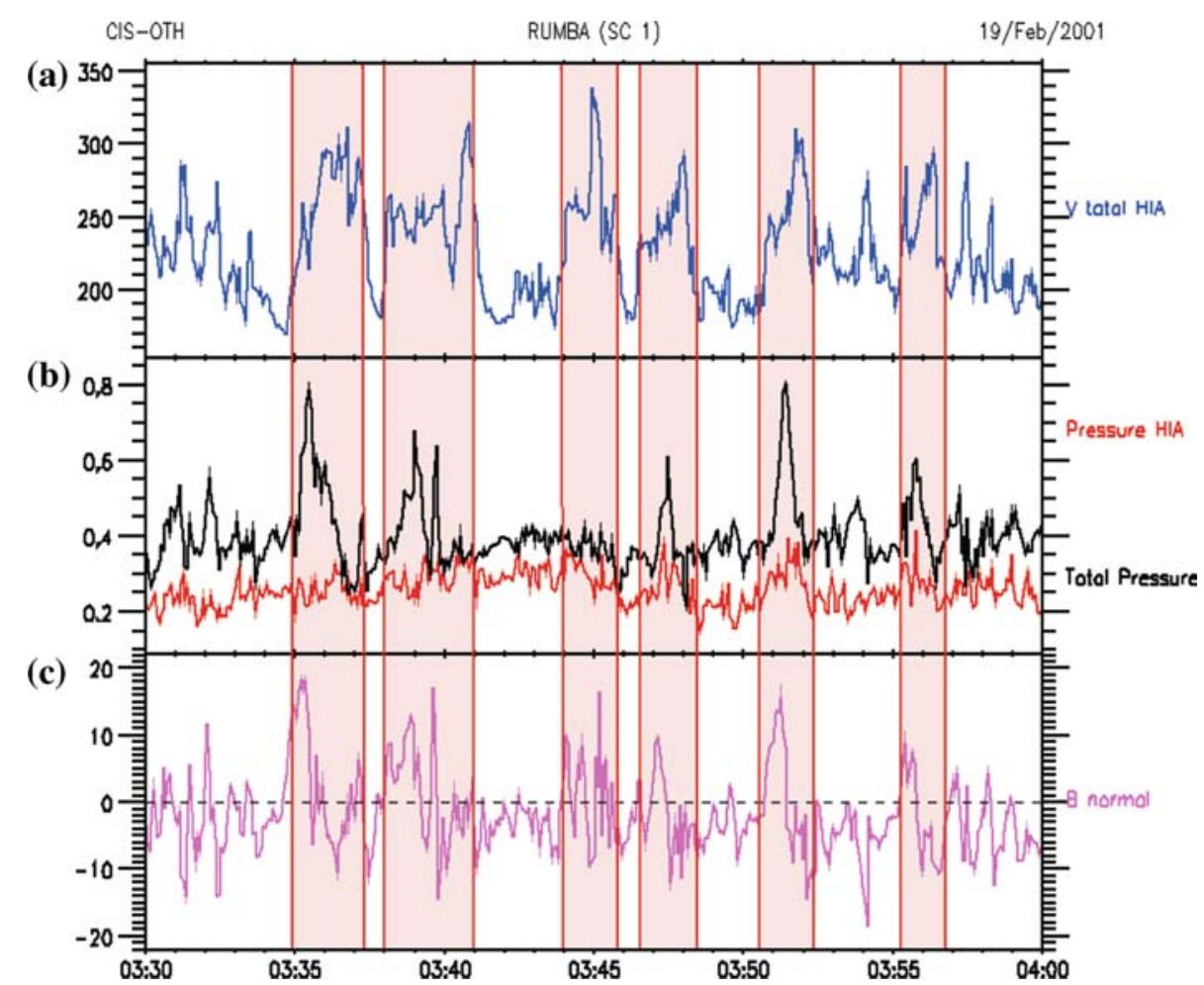

Figure 9. This plate displays Cluster measurements for a magnetosheath pass on 19/02/2001 that shows FTE like signatures. The magnitude of the HIA (all ions) velocity is shown in panel a. The ion pressure from HIA $\left(\mathrm{Nk}_{\mathrm{B}} \mathrm{T}\right)$ and the total pressure (ion plus magnetic pressure, from FGM) are displayed in panel b. The magnetic field component in the normal (to the magnetopause) direction is presented in panel c. 
Whether such structures may imply a merging process is uncertain. A key in understanding the cusp and plasma mantle structures may remain the exact characterization of the processes which drive plasma intrusion into the magnetosphere. The occurrence of spatially steady structures more particularly in the high-altitude plasma mantle region may shed new lights on their origin.

\subsection{ReCONNECTION, FTEs AND PTEs}

As observed on $04 / 02 / 2002$, the magnetic field shows no boundary normal component at the exterior cusp-dayside plasma sheet boundary (21:43 UT). On the other hand, the outer discontinuity with the magnetosheath is apparently rotational. The normal magnetic field had a negative sign, as compared to the outward pointing normal. This is compatible with lobe reconnection occurring above the spacecraft location. The de HoffmannTeller analysis and the Walén test success shown by Lavraud et al. (2002) are also in agreement with this interpretation. The discontinuity characteristics were further shown to be stable over the four Cluster spacecraft. Finally, large plasma flows were continuously detected at the poleward edge of the high-altitude cusp. These flows have a negative $\mathrm{V}_{y}$ component, thus opposite to the IMF $\mathrm{B}_{y}$ at that time (Figure $4 \mathrm{e}$ and $\mathrm{h}$ ). All these arguments are suggestive of a possibly steady reconnection site.

The occurrence of sporadic, patchy reconnection events, however, is thought to be important since the first observational evidence of Russell and Elphic (1978). Such events are called flux transfer events (FTEs). During the $19 / 02 / 2001$ event we presented, such signatures possibly occur after the magnetopause crossing. Several plasma accelerations, that are well correlated with magnetic field disturbances in all three components, are seen between 03:30 and 04:00 UT in Figure 2e and g. The upward and tailward velocities are consistent with the southward IMF (Figure 2h), as monitored by ACE. The feature thus appears to be compatible with possible dayside reconnection. Figure 9 shows time series of HIA and FGM measurements zoomed in this interval. Panel a displays the magnitude of ions bulk velocity. Total (ion plus magnetic) and ion $\left(\mathrm{Nk}_{\mathrm{B}} \mathrm{T}\right)$ pressures are shown in panel $\mathrm{b}$, while the magnetic field component normal to the magnetopause is shown in panel c. The FTE like events are bounded between the red vertical lines and are shaded. These transients show a bipolar signature of the Bn component as well as an enhanced bulk velocity. Panel $b$ displays a quasi-continuous ion pressure while an excess magnetic pressure is measured at each event. These observations highlight the main characteristics of such transient structures, which supposedly are FTEs. Unfortunately, the inter-spacecraft separation of $\sim 600 \mathrm{~km}$ is small (FTEs are often $\sim 1 R_{\mathrm{E}}$ ) and does not allow to study the spatial behavior of the ionic structure through the spacecraft array. It may be 
noted that a similar pass through FTE signatures is fully discussed in a recent paper using Cluster data by Bosqued et al. (2001). These authors provided convincing evidence for the probable prominent role of transient reconnection.

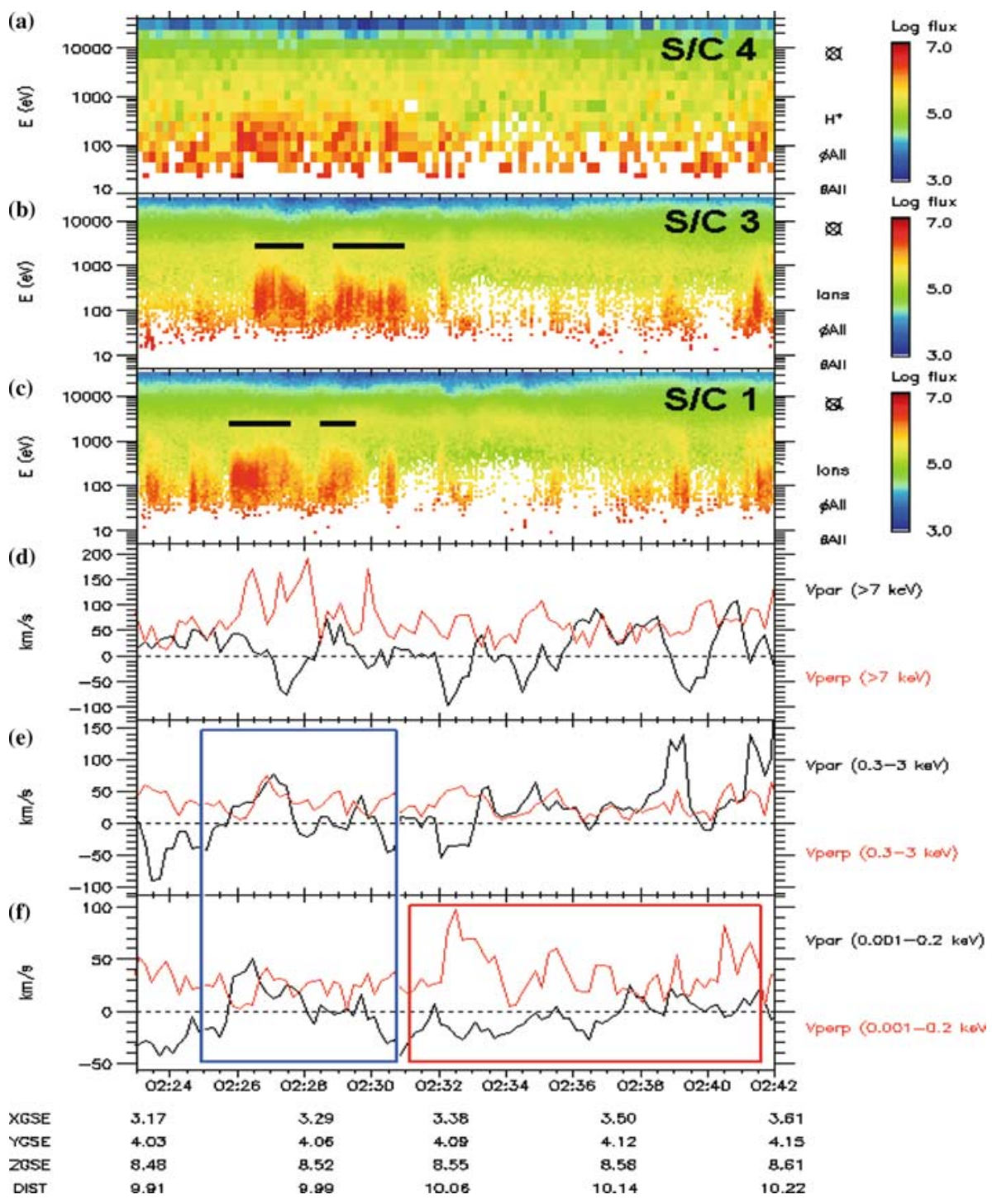

Figure 10. This plate presents the observations of possible evanescent PTEs (during the surrounded blue part) as well as intermittently accelerated cold plasma (during the surrounded red part). The first panel is the spectrogram from CODIF $\mathrm{H}^{+}$onboard spacecraft 4 , panel $\mathrm{b}$ is that of HIA (all ions) onboard spacecraft 3 and panel c shows the HIA spectrogram for spacecraft 1 . The parallel velocity and the magnitude of the perpendicular velocity computed from HIA measurements onboard spacecraft 1 are shown for three different energy ranges in panels d, e and f. Energy ranges are respectively: $>7 \mathrm{keV}, 0.3-3 \mathrm{keV}$ and $<0.2 \mathrm{keV}$. 
The possibility of plasma protrusion through the magnetopause without necessity of magnetic merging was early proposed by Lemaire and Roth (1978) (see also Roth (1992)). This process is an alternative to the reconnection model. We therefore want to highlight typical observations of such possible plasma transfer events (PTEs) (Lundin et al., 2003).

Figure 10 displays a zoom in of the 02:24-02:35 UT interval during the 19/02/2001 event. It shows transient detection of magnetosheath like plasma on apparently dayside magnetospheric field lines, that are mixed with highenergy ions of plasma sheet origin. The two main transients, observed between 02:26 and 02:32 UT, are composed of $\mathrm{H}^{+}$and $\mathrm{He}^{2+}$ ions mainly (not shown) within the energy range $0.3-3 \mathrm{keV}$, revealing they are most probably of magnetosheath (solar wind) origin. Panels a , b and c respectively show the spectrograms from spacecraft 4 (CODIF), 3 (HIA) and 1 (HIA). We used several energy ranges in computing the velocity moment for spacecraft 1 (only) in panels $\mathrm{d}$, e and $\mathrm{f}$. These energy ranges have been chosen to fit the three different populations observed during the interval. Energy $>7 \mathrm{keV}$ shows the behavior of the most energetic plasma sheet ions. The 0.3-3 keV range highlights that of the magnetosheath like plasma while the $<0.2 \mathrm{keV}$ range is representative of the coldest populations intermittently observed (discussed in the next subsection).

The PTE signatures presented in Figure 10 between 02:25 and 02:32 UT show nearly fully mixed populations. Here we focus on the most intense signature at 02:26-02:28 UT. It is characterized by rather low flows (see the surrounded part in blue of panels e and f) with equivalent parallel and perpendicular magnitudes in both the medium and low energy ranges. Panel d shows, however, that the perpendicular velocity of the high-energy ions is very different from those of the low and medium energy components. For high-energy ions the gradient/anisotropy, due to their large gyroradii, has strong influence on the perpendicular velocity while lower energy ions are mostly drifting in the ExB sense. In accordance with the characteristics given by Lundin et al. (2003), this particular case shows rather "evanescent" PTE signatures. Indeed, according to these authors the "active" PTEs have important drift velocities and show little (magnetosheath and plasma sheet) plasma mixing while their drift velocities are decreased (braking) and plasma mixing is large when "evanescent". These authors therefore suppose that "evanescent" PTEs should have reached the most inward magnetospheric field lines, such as is probable in the case presented in Figure 10.

The Cluster spacecraft observed PTE like events on 14/01/2001. Lockwood et al. (2001b) interpreted them as LLBL encounters. These observations revealed a clear nested feature in the time series. This favors the interpretation of LLBL being permanently attached to the cusp (and magnetopause) boundaries, and possibly due to ongoing dayside, sub-solar reconnection. However, because the PTEs are supposedly detached small 
plasma blobs convected within the magnetosphere, their signatures in the time series should be lagged, and not nested. The events presented by Lundin et al. (2003) apparently presented such characteristics. In Figure 10, spacecraft 1 and 3 (panel $\mathrm{c}$ and $\mathrm{b}$ respectively) detected such two successive transients (shown with black lines). Spacecraft 4 data had low resolution during this event and did not permit to isolate the two events. These two events appear to be lagged in time between the two spacecraft, but with different durations at spacecraft 1 and 3. Taking into account the spacecraft location, these structures might be detached, spatially limited and convected towards the inner magnetosphere, but a definitive conclusion can not be made at all in the present case. As revealed through the case shown by Lockwood et al. (2001b), further multi-spacecraft analysis is needed to infer their spatial extent, and single event analysis is may be insufficient.

It has been suggested that PTE signatures inside the magnetosphere and FTE signatures at the magnetopause (and magnetosheath) may be subsequent to a unique process (Lundin et al., 2003). An argument that may favor the PTEs independent nature is however that they are often sampled deep inside the magnetosphere, showing fully mixed plasma (as in Figure 10), as well as near the magnetopause, showing a depletion in magnetospheric population fluxes. Moreover, Stenuit et al. (2001) and Lundin et al. (2003) found a poor correlation of their occurrence with IMF orientation. Merged flux tubes may not account for such properties, particularly under southward IMF when FTEs supposedly are quickly convected tailward. Some expected differences in the observational signatures of FTEs and PTEs were reviewed by Lui (2001). The possible occurrence of reconnection, FTEs, gyroradius effects, diffusion, Kelvin-Helmholtz instability and PTEs at the magnetopause were recently revisited by Sibeck et al. (1999).

\subsection{INTERMitTENT COLD PLASMA ACCELERATIONS}

Thermal cold plasma accelerations were first revealed in Cluster data aside the flank magnetopause by Sauvaud et al. (2001). Lundin et al. (2003) later emphasized similar phenomena occurring near and within PTE signatures. Here we show their occurrence near the high-altitude cusp, both during the presence and absence of entering magnetosheath plasma.

Figure 11 is showing an interesting pass through the high-altitude cusp boundary layers and dayside plasma sheet on 19/02/2001. The energy-time spectrogram of panel a highlights the presence of cold ions below $100 \mathrm{eV}$ during most of the interval. Most particularly, a mixture of magnetosheath like $(\sim 1000 \mathrm{eV})$ and accelerated cold $(<100 \mathrm{eV})$ ions is clearly observed from 03:06 to 03:07 UT (also present is the high-energy component from the plasma sheet). A distribution function is displayed in Figure 12 at 03:06:30 UT. It shows three distinct plasma populations. A trapped 


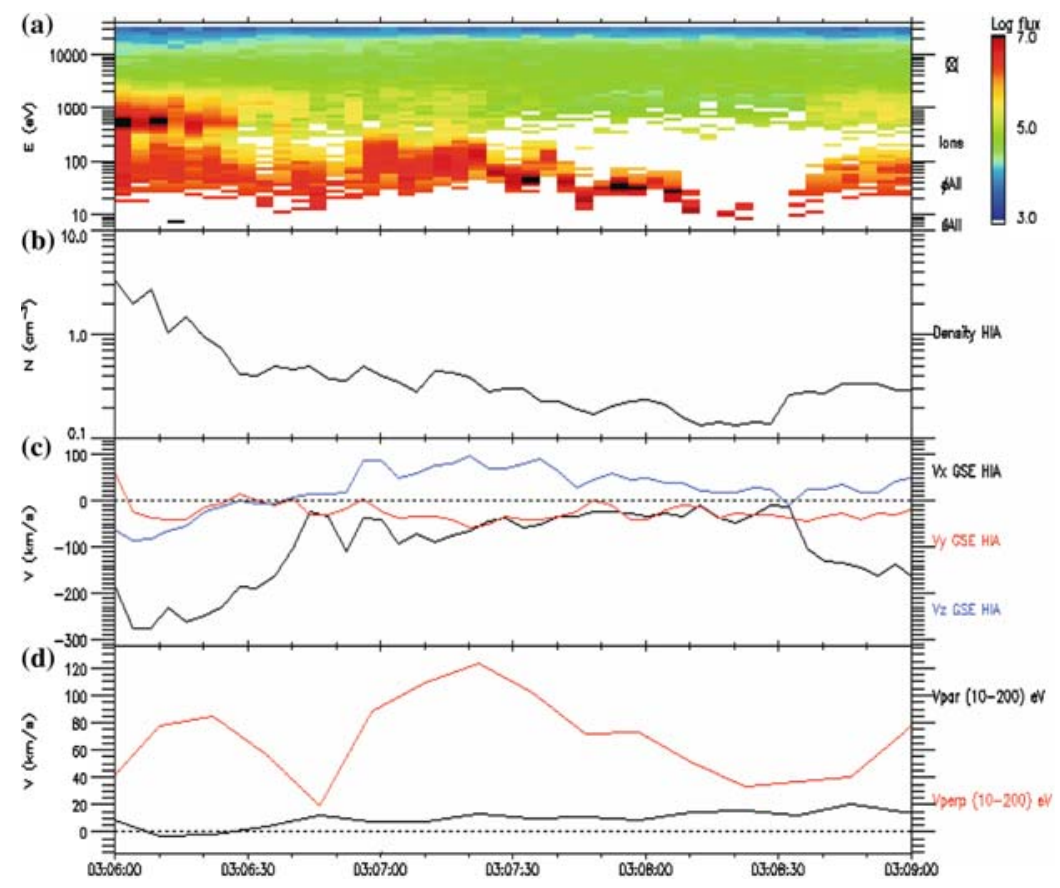

Figure 11. This plate presents cold ion observations near the high-altitude cusp boundary on $19 / 02 / 2001$, that are sometimes mixed with magnetosheath and plasma sheet ion populations. Panel a shows the energy-time spectrogram from HIA. Panel b and c display the moments: the ions density and the ions bulk (whole energy range) velocity in GSE. The last panel shows the parallel and perpendicular to the magnetic field magnitudes of the ions velocity, computed for the range of energy $(10,200) \mathrm{eV}$ only. This last panel thus highlights the cold ions population behavior more specifically.

high-energy component, that is typical for the dayside plasma sheet, is seen as the quasi-isotropic background at high energies (which extends further than the axes limits). A second, intense population flowing mainly along the magnetic field is observed. It is a typical magnetosheath plasma flow that apparently had access to magnetospheric field lines. There also appears a colder ion population, that is shown to be totally perpendicularly drifting. Lundin et al. (2003) recently showed a similar co-existence of three distinct populations, on apparently typical dayside magnetospheric field lines within the magnetopause boundary layers. Hence similar to the present case.

However, it is clearly seen in Figure 11 that cold ions are also observed without the direct presence of entering magnetosheath plasma. Such ions are detected between 03:07:30 and 03:08:30 UT. The transition from a mixture of magnetosheath like and cold plasma to uniquely cold plasma appears gradual. The cold ions are clearly accelerated in the perpendicular direction only, according to panel $\mathrm{d}$. The feature shows an energy dispersion in panel a between 03:07:30 and 03:08:30 UT. While they are widely present near the 

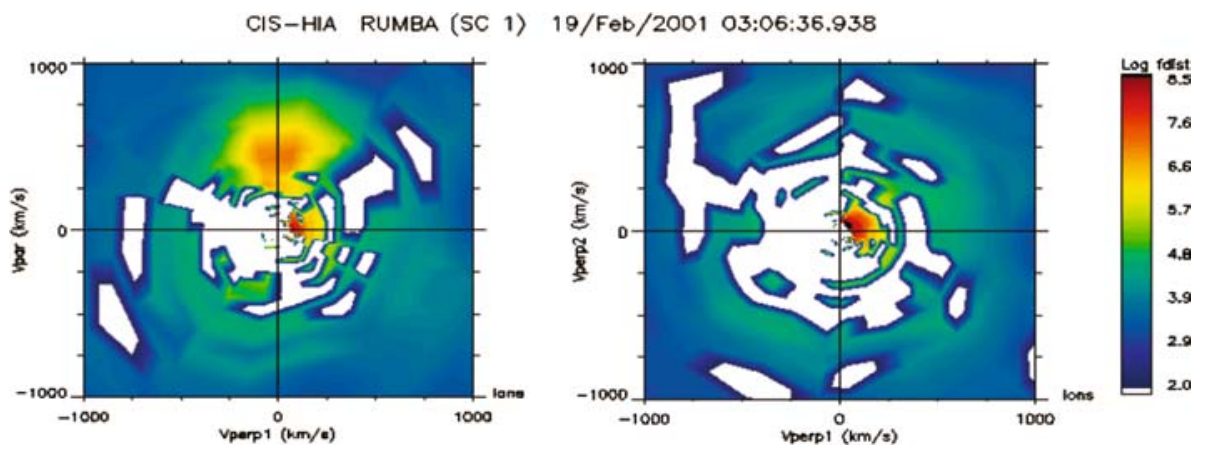

Figure 12. Similar ion distribution function to that of Figure 2a. It is sampled near the exterior cusp and dayside magnetopause, inside what appears to be boundary layers on 19/02/ 2001 at $\sim 03: 06: 36$ UT onboard spacecraft 1 . It shows a mixture of three different populations (see text).

cusp boundary layers, their energy decreases with increasing depth within the dayside plasma sheet and they finally disappear at $\sim 02: 08: 30$ UT.

The intermittent nature of cold plasma acceleration is evidenced in Figure 10, between 02:31 and 02:41 UT. During this interval the ions are only detected sporadically. The cold ion population is again totally flowing perpendicular to the magnetic field (panel $\mathrm{f}$, the parts surrounded in red). The perpendicular velocity is very similar in all energy ranges during the times when accelerated cold ions are observed (02:31-02:41 UT). This is evidence for the role of an electric field providing acceleration via ExB drift. This allows the cold population to become detectable to the CIS instrument.

To account for the acceleration of cold plasma near the flank magnetopause, Sauvaud et al. (2001) suggested that magnetopause current motions inwards and outwards are susceptible to induce local electric fields (Faraday"s law) that would act to accelerate the local cold plasma. On the other hand, Lundin et al. (2003)'s approach of PTEs implies the creation of an electric field resulting from depolarization after magnetosheath plasma has protruded the magnetopause. Acceleration of local cold plasma subsequent to impulsive plasma penetration, as was early envisaged by Lundin and Dubinin (1985), is thus substantially different from the former process, although not mutually exclusive.

When magnetosheath plasma is not present, we may expect the acceleration to be induced by current sheet motions. The energy-dispersed feature may thus be linked to temporal, i.e. boundary motion changes, or spatial effects, since the induced electric field strength depends on distance from the current sheet.

Both Sauvaud et al. (2001) and Lundin et al. (2003) reported the large occurrence of cold plasma detection in the Cluster data. Sauvaud et al. (2001) 
gave evidence that a cold plasma component was probably existing although too cold to be detected within the CIS dynamical range during their observations. During their event, when CIS stopped detecting these ions, the Whisper instrument (Décréau et al., 2001) was still sensing nearly equal densities near the magnetopause. The cold ions thus become detectable to CIS in the presence of enhanced electric fields. This indirect sensing of cold populations should permit in the future to highlight the spatial extent and the characteristics of the source region. Although not presently shown, the cold plasma is most of the time made of $\mathrm{H}^{+}, \mathrm{He}^{+}$and $\mathrm{O}^{+}$ions, which rules out the solar wind as a source. Possible sources are the plasmasphere or more directly the ionosphere, both from the dayside and nightside parts of the auroral oval, including the cusps (Sauvaud et al., 2001; Lundin et al., 2003).

\subsection{ENERGETIC IONS IN THE EXTERIOR CUSP DIAMAGNETIC CAVITY}

The high-altitude cusp region is known to contain substantial fluxes of highenergy ions (from tens of $\mathrm{keV}$ to $\mathrm{MeV}$ ), comparable to the populations observed in the dayside plasma sheet (Kremser et al., 1995; Chen and Fritz, 2001; Chang et al., 2001; Trattner et al., 2001; Fritz et al., 2003). In this paper we take advantage of the CIS CODIF composition measurements to establish the detection of a distinct high-energy ions population, from $5 \mathrm{keV}$ up to $40 \mathrm{keV}$, in the cusp diamagnetic cavity. Two typical energy spectra are shown for the 04/02/2001 inside the exterior cusp cavity, for $\mathrm{H}^{+}$ions in Figure 13a and for $\mathrm{O}^{+}$ions in Figure 13b. For both $\mathrm{H}^{+}$and $\mathrm{O}^{+}$ions a clear spectral break is observed at $\sim 5 \mathrm{keV}$ in the flux curves. The populations are not extensions of the magnetosheath plasma (centered at few hundreds $\mathrm{eV}$ ). Together with the fluxes (line plots) shown in the observation section for the $19 / 02 / 2001 \mathrm{H}^{+}$and $04 / 02 / 2001 \mathrm{O}^{+}$events, the present data thus give evidence for the presence of a distinct high energy ion population in the exterior cusp in the range (5-40) $\mathrm{keV}$.

High-energy ions $(>5 \mathrm{keV})$, mixed with plasma of magnetosheath origin are present during those two events. In the exterior cusp itself (low magnetic field region), their fluxes are lower than in the adjacent dayside plasma sheet. They are also lower than in the adjacent boundary layers, if they exist, as for the $19 / 02 / 2001$ event. During the various passage through the plasma sheetboundary layers-exterior cusp boundaries described in the observation section, a consistent gradual transition in these fluxes is always observed. All these ions are however absent when the spacecraft are sufficiently far out in the magnetosheath proper. They are also absent in the tenuous lobes for both events.

To account for the presence of energetic ions above $40 \mathrm{keV}$ (and up to $\mathrm{MeV}$ ) in the cusp region, several sources have been proposed: the solar wind (Chang et al., 2001; Trattner et al., 2001), the ionosphere (via an energization process) (Chen and Fritz, 2001; Fritz et al., 2003) and the dayside plasma 

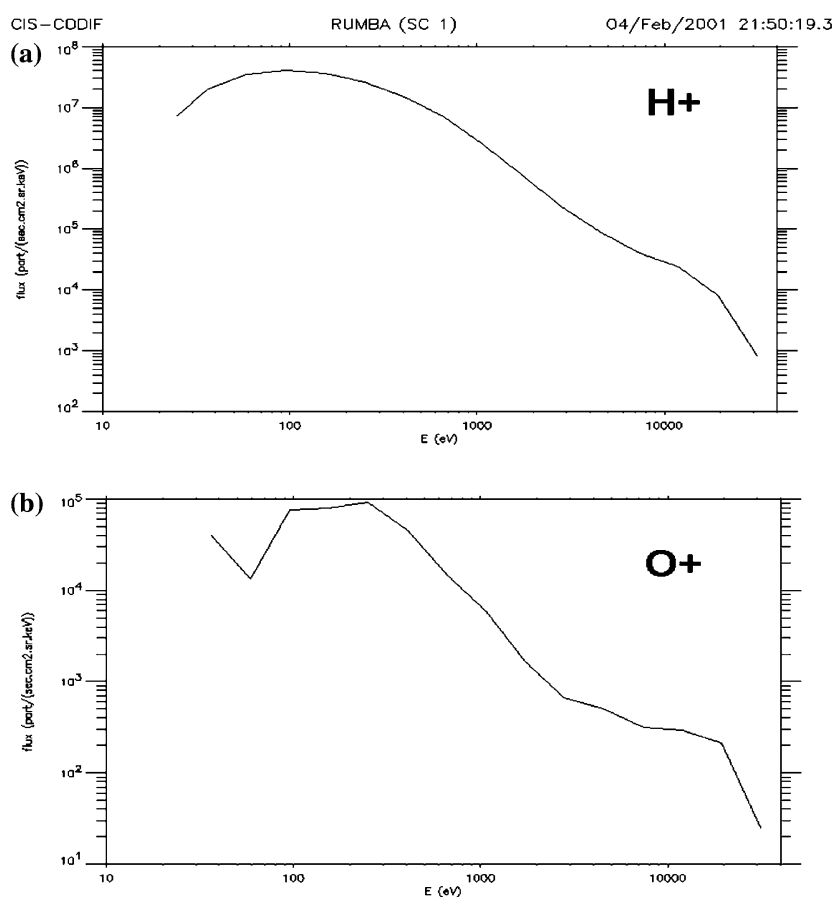

Figure 13. Energy spectra of the $\mathrm{H}^{+}$and $\mathrm{O}^{+}$fluxes in the exterior cusp diamagnetic cavity on 04/02/2001 around 21:50 UT. It clearly reveals the presence of a high-energy population above $5 \mathrm{keV}$ for both ions.

sheet (Kremser et al., 1995; Delcourt and Sauvaud, 1998, 1999). We deal here with their possible role in the context of the $5-40 \mathrm{keV}$ ions detected by the Cluster CIS CODIF instrument.

First, very few $\mathrm{O}^{+}$ions are a priori present in the solar wind. Substantial amounts of $\mathrm{O}^{+}$ions in the exterior cusp thus reject the solar wind as the source. Concerning the $\mathrm{H}^{+}$ions, the solar wind source appears unlikely in these particular cases because of the very low fluxes observed slightly later when Cluster sampled the magnetosheath. Some link with IMF orientation in the magnetosheath, however, may not be excluded (Trattner et al., 2001). Secondly, the constant gradual decrease of the fluxes between the dayside plasma sheet and the exterior cusp may not be expected if the ions where coming from the magnetosheath. The ions would be susceptible to enter all way long through the exterior cusp-magnetosheath boundary and therefore should not present such peculiar distributions.

An ionospheric source could explain the $\mathrm{O}^{+}$population. To account for the tens of $\mathrm{keV} \mathrm{O}^{+}$(and up to $\mathrm{MeV}$ ) detected by the Polar spacecraft, Chen and Fritz (2001) proposed a local energization process for ionospheric ions that would involve low frequency magnetic turbulence. On 04/02/2001 some 
low frequency turbulence is observed throughout the cusp in the magnetic field data (Figure 4g). It is weaker, however, in the most distant part of the exterior cusp (low field region). These $\mathrm{O}^{+}$therefore may not be energized in this distant exterior cusp (i.e. Stagnant Exterior Cusp (Lavraud et al., 2002)). Acceleration process may however occur at lower altitudes. For instance, Bogdanova et al. (2004) recently showed the probable occurrence of cusp ion outflow heating via low-frequency electric field waves, permitting $\mathrm{O}^{+}$ accelerations up to $\sim 1 \mathrm{keV}$ at most. Several studies have shown observations of low frequency electromagnetic waves in the mid and high-altitude cusp (Angelopoulos et al., 2001; Le et al., 2001; Pickett et al., 2001). But how some wave particle interactions could energize ions to tens or hundreds of $\mathrm{keV}$ (Chen and Fritz, 2001; Fritz et al., 2003) is still to be determined (Angelopoulos et al., 2001). Finally, the gradual behavior of the flux decrease at the exterior cusp boundaries also is incompatible with a unique ionospheric source interpretation.

The similar behavior of both species throughout the cusp passes suggests a common origin for the two species. Also, the presence of high energy $\mathrm{O}^{+}$ strongly favors that the magnetosphere (or ionosphere) may be the source of the cusp energetic ions in the present cases. But how magnetospheric ions gain access to the cusp needs to be explained.

During roughly southward IMF (19/02/2001), reconnection could possibly result in their access to the cusp since the dayside closed magnetospheric field lines contain such a high energy plasma. However, during northward IMF, reconnection may take place poleward of the cusp, as expected for the $04 / 02 / 2001$ case. But the absence of energetic ions in the lobes rules out the nightside magnetosphere as a source. We may not rule out, nevertheless, the occurrence of reconnection equatorward (or sideways) of the cusp (and possible component merging process) which would also allow dayside magnetospheric ions to enter the exterior cusp via open field lines. However, Lavraud et al. (2002), as well as the present observations, rather favor long-term ongoing lobe reconnection during the 04/02/2001 event. The possible implication of a merging process needs further investigations.

The gradual decrease of the energetic ion fluxes away from the peak in the plasma sheet during both events tend to suggest a simple leakage across the dayside plasma sheet-exterior cusp boundary, possibly due to their large gyroradii. The presence of high-energy ions of magnetospheric origin at high latitudes was recently investigated via simulations by Delcourt and Sauvaud, 1998, 1999). They showed that the combined effect of convection, gradient/ curvature drifts and the off-equator magnetic field minimum (due to the solar wind pressure at the sub-solar magnetopause) may allow high-energy ions (tens to hundreds $\mathrm{keV}$ ) to escape into the high-latitude cusp region. In fact the observations during both events have shown the presence of high-energy ions of plasma sheet origin on the dayside magnetospheric field lines, and 
within the possible boundary layers, just adjacent to the cusp diamagnetic cavity. This population is thus simply separated from the exterior cusp by a sharp boundary (for instance a TD). Leakage towards the cavity may then occur, owing to their large gyroradii. Using the Viking ion data, Kremser et al. (1995) showed an equivalent high-energy ion gradual behavior at the cusp-dayside plasma sheet transition at lower altitudes. They proposed that most of the high-energy $\mathrm{H}^{+}$fluxes (up to $50 \mathrm{keV}$ ) is of plasma sheet origin.

Nevertheless, none of the above hypothesis may be ruled out to explain the presence of high energy $(5-40 \mathrm{keV})$ ion populations in the cusp. This high-energy plasma may have several origins, and that probably depend on the energy range as suggested by Trattner et al. (2001).

\subsection{THE EXTERIOR CUSP STRUCTURE AND ITS INTERFACE WITH THE MAGNETOSHEATH}

The 04/02/2001, 19/02/2001 and 18/05/2001 events represent good cases in order to highlight the global structure of the exterior cusp and its surrounding. Under steady northward IMF on $04 / 02 / 2001$ the exterior cusp was bounded on its poleward edge by large flows. The sunward convection was well evidenced and the $\mathrm{V}_{y}$ component of the flows has an opposite sign to the IMF $\mathrm{B}_{y}$ (Figure $4 \mathrm{e}$ and $\mathrm{h}$ ). No plasma mantle was present. This picture thus appears compatible with expectations for lobe reconnection. On the other hand, the 19/02/2001 event was characterized by an energy dispersion suggestive of a weak convection directed tailward (and as observed in the flows). This is consistent with the presence of a plasma mantle at the poleward edge of the cusp. Although the IMF $\mathrm{B}_{z}$ component varied around $0 \mathrm{nT}$ during most of the interval (Figure $2 \mathrm{~h}$ ), the positive IMF $\mathrm{B}_{x}$ component suggests that the draped magnetosheath field at the dayside of the magnetosphere has a downward orientation. Hence, we may expect the magnetosheath and magnetospheric field to be anti-parallel at the dayside magnetopause, possibly allowing sub-solar reconnection.

On $04 / 02 / 2001$, the large flows on the poleward side of the high-altitude cusp were followed by an exterior cusp pass, showing depressed magnetic field and stagnant plasma. The dynamics of the cusp allowed the Cluster spacecraft to make a quick exit into the dayside plasma sheet. It shows that the diamagnetic cavity (exterior cusp) was separated from the dayside plasma sheet by a sharp boundary. A similar boundary was present on 19/02/2001 between the exterior cusp and the dayside plasma sheet (or rather boundary layer) during the quick exit seen around 03:00 UT. The boundaries had a tangential nature in both events. Boundary layers were observed at the equatorward edge of the diamagnetic cavity on 19/02/2001, for instance between 02:45 and 02:55 UT. The magnetic field had a typical magnetospheric orientation and strength there, and a field aligned flow was observed (see 
Figure $2 b$, e and g). These may be called the LLBL. Contrarily, no such boundary layers were observed at the dayside plasma sheet-exterior cusp interface on 04/02/2001. These observations appear to be compatible with a plasma entry process through the dayside magnetopause for southward IMF, which would not take place (at least at the dayside magnetopause) under northward IMF conditions. This process may be reconnection.

According to Vasyliunas (1995) the exterior cusp cannot be stagnant. He invoked subsolar reconnection and the probable subsequent tailward convection to account for the global cusp topology and characteristics. Under this context, the magnetosheath plasma gets access to the exterior cusp through the RD (an Alfvén wave) created in the subsolar region and propagating tailward over the cusps. The exterior cusp is thus filled with magnetosheath plasma, convecting at a speed attaining a non-negligible fraction of the external magnetosheath flow. However, this interpretation does not take into account the possibility of lobe reconnection under northward IMF. This could lead to the presence of a discontinuity, possibly then a counterstreaming (relative to the magnetosheath) Alfvén wave, moving very slowly sunward and downward. The downstream plasma may then be much more stagnant, as observed on $04 / 02 / 2001$. The very low perpendicular velocity (not shown) in the (stagnant) exterior cusp on $04 / 02 / 2001$ is on average oriented towards the dayside and the external boundary de Hoffmann-Teller frame is consistently found to be moving slowly sunward and downward (see Lavraud et al., 2002).

On the other hand, although a southward like orientation of the magnetosheath field is expected, and a global tendency of tailward convection in the cusp and plasma mantle that has previously be noted, stagnant plasma was also observed in the exterior cusp on 19/02/2001. This shows that plasma stagnation may occur in the exterior cusp even under conditions of such apparent global tailward convection. A plausible interpretation is that the exterior cusp is more stagnant because permanently made of co-existing up and down-flowing magnetosheath plasma. Part of the plasma is pre-existent. The plasma located within this very low magnetic field region appears thermalized, a heating process seems to occur at the boundary (Lavraud et al., 2002). It is unclear whether the possible occurrence of reconnection is relevant to explain these characteristics. Such a "stagnation region" had early been predicted by Spreiter and Summers (1967) and observed by HEOS 2 (Haerendel et al., 1976). It was interpreted in terms of aerodynamic behavior. Yamauchi and Lundin (1997) further emphasized the possible role of plasma inertia and escaping ions for the presence of stagnant plasma. The intriguing appearance of stagnant plasma on 19/02/2001 thus may be an argument against the role of reconnection in structuring the cusp, which may be an over-simplified view. The occurrence of plasma stagnation in the 
exterior cusp as a function of solar wind conditions therefore deserves much interest.

In Figure 14 we display the plasma, magnetic and total pressures during the interval 21:35-22:05 UT in panel a. The time series of the magnetic field magnitude for the four spacecraft are shown in panel $\mathrm{b}$. The nested nature of the dayside magnetospheric encounter at 21:41-21:45 UT is evidenced in panel $b$. The magnetic pressure increases in this region while the plasma pressure decreases. On average, the total pressure is conserved. This highlights an equilibrium between the two regions.

Cargill (1999) and Taylor and Cargill (2001) investigated the theoretical possible occurrence of shocks in the near cusp magnetosheath flow. This was first investigated by Walters (1966). However only possible intermediate and slow shock-like signatures have been reported near the cusp and magnetopause (but not established) in the literature so far (Song et al., 1992; Whaltour et al., 1995; Dubinin et al., 2002; Lavraud et al, 2002). On 04/02/2001, the exterior cusp-magnetosheath boundary may be the result of reconnection in the lobes as emphasized by Lavraud et al. (2002). The boundary would possibly be a RD originating from a reconnection site located above the

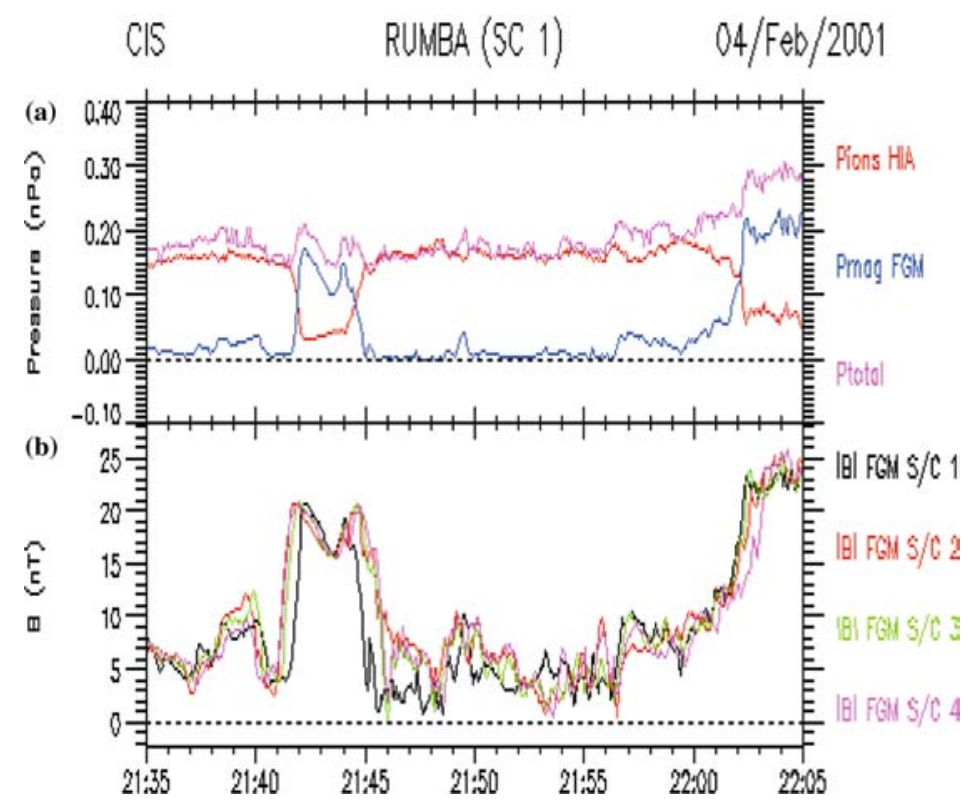

Figure 14. Pressures and four spacecraft magnetic field time series for an interval including the main magnetic boundaries crossed on $04 / 02 / 2001$. The nested feature observed at 21:4121:45 UT is the dayside plasma sheet encounter. The boundary observed at 22:02 UT is the external current sheet between the exterior cusp and the magnetosheath. The ion pressure from HIA $\left(\mathrm{Nk}_{\mathrm{B}} \mathrm{T}\right)$, the magnetic pressure (from FGM) and the total pressure are displayed in panel a. The magnetic field strength from FGM is presented in panel $b$ for the four spacecraft. 
spacecraft (Fuselier et al., 2000; Russell et al., 2000; Onsager et al., 2001). This boundary is indeed shown to be a sharp boundary, rotational in nature and it allows plasma entry into the cusp and subsequently the magnetosphere. But the magnetosheath plasma appears heated right at the boundary, what should not be expected at usual MHD RDs. Because of the pre-existence of out-going hot exterior cusp plasma that mixes with the entering magnetosheath plasma, the distribution functions sampled on the inside of the boundary appear quickly isotropic. This also reveals that the boundary is very complex. More comprehensive analysis will be devoted to understanding the physics of this key boundary in future papers.

Because the exact origin and nature of the discontinuity are unclear, it may be more cautious to define the magnetopause as the boundary delimiting the exterior cusp from the dayside plasma sheet (see Figure 1b). This is the definition given by Russell et al. (2000). Note that if reconnection plays a crucial role in structuring the cusp at large scale and that the external boundary is the result of this process, it may be reasonable calling the exterior cusp-magnetosheath boundary the magnetopause, which is the definition of Onsager et al. (2001). And subsequently, the "exterior" cusp we dealt within this paper would be located "interior" to the magnetopause.

\section{Conclusions}

We presented in Figure $1 \mathrm{~b}$ a schematic of the Cluster path for all three events: $19 / 02 / 2001,04 / 02 / 2001$ and 18/05/2001. Their different actual paths through the various regions of the high-altitude magnetosphere in the cusp region have allowed a global investigation of the high-altitude cusp and its surrounding in a complementary way. We presented and analyzed the overview of typical Cluster observations in the region for different solar wind conditions. From this study, we may conclude the following.

We have described in details the high-altitude cusp precipitation region properties. The large-scale energy dispersion features and the associated large-scale convection appear to be dependent on the IMF orientation. The short time-scale plasma flows showing a pitch angle evolution in accordance with mirroring at low-altitude highlight the time-dependent nature of plasma injections in the cusp region. The current spatial-temporal ambiguity concerning "cusp ion step" like structures was pointed out and further illustrated through the analysis of the 18/05/2001 event. While such features were previously recorded with dual satellites at low or mid-altitudes, we have shown the probable occurrence of such spatial structure in the highaltitude plasma mantle. The multi-spacecraft Cluster data can play a significant role in trying to fix their spatial and temporal characteristics as well as to infer their origin. 
The possible occurrence of steady reconnection in the lobes was pointed out. However, a current space physics controversy was discussed in terms of the exact characterization of the processes allowing for plasma entry into the magnetosphere. The FTE and PTE observations are possibly due to the same, unique process. These two different interpretations might reveal a certain duality in plasma physics (Lui, 2001). Anyhow, the clear transient nature of plasma penetration into the magnetosphere (and cusp) implies dynamical processes, that steady state interpretations may not support.

We have shown observations of accelerated cold plasma at locations where dynamical, kinetic effects are susceptible to generate electric fields. They were shown to be observed intermittently in this region, and both during the presence and absence of entering magnetosheath plasma. The processes susceptible to generate these electric fields (induced by magnetopause motions or following a depolarization generated by protruding plasma), as well as the origin of the cold ions (plasmasphere or ionosphere), are still unclear. The combined use of the different, complementary instruments onboard the multi-spacecraft Cluster mission will probably allow a better comprehension of these phenomena in the near future. The density of this cold plasma is often large, as pointed out by Sauvaud et al. (2001). Because these are not always detectable within classical particle detector energy ranges, the investigation of their possible permanent presence is crucial for the physics of the whole magnetosphere. In low density regions, the spacecraft potential is too high to permit the detection of this thermal population that is only of a few $\mathrm{eV}$ most of the time. Finding a way to limit the spacecraft potential is a major issue.

The presence of distinct populations (both $\mathrm{H}^{+}$and $\mathrm{O}^{+}$components) of high energy ions (5-40 keV) inside the exterior cusp has been evidenced by use of the Cluster CIS CODIF instrument. As presented here, several reasons for their presence may be found in the literature. The ionosphere (provided some acceleration process exists) and the bow shock have been proposed as possible source regions. The present observations, however rather favor the dayside plasma sheet as a seed population for $\mathrm{H}^{+}$and $\mathrm{O}^{+}$ions at these energies. How leakage may occur would also need be addressed. Single event studies may not permit to understand the actual origin of these ions. More surveys are needed to try to discriminate between those alternate views, or at least between their relative importance.

We finally gave an overview of the cusp large-scale picture. The global cusp convection is linked to the interplanetary conditions and there are evidence for its implication in structuring the cusp and its surrounding regions (presence or absence of boundary layers). The exterior cusp is surrounded by clear boundaries, with the lobes, the dayside plasma sheet and the magnetosheath. This distant region is always characterized by a strong magnetic depletion, which is partially the result of diamagnetic effect. The further out the space- 
craft are, the more stagnant the plasma appears on $04 / 02 / 2001$. In addition to a presumably low field at the null point of the Chapman Ferraro model (Chapman and Ferraro, 1931) the magnetosheath population that fills the region provides an excess plasma pressure. It is balanced by substantial diamagnetic effect and the cavity is formed, in apparent equilibrium with its surrounding. Whether reconnection occurs and can explain part of the cusp structure needs to be fixed in the future. For matter of caution, it may be preferable to define the magnetopause as the indented boundary between the exterior cusp and the magnetosphere itself. But if reconnection drives the large-scale cusp structure and topology, the exterior cusp-magnetosheath boundary depicted here may rather be called the magnetopause, implying that the so-called "exterior cusp" is inside the magnetopause.

The global structure, the magnetic field topology and the dynamics of the high-altitude cusp region and its surrounding boundaries are keys to understanding how solar wind plasma enters the magnetosphere. The Cluster data have showed an unprecedented potential for the characterization of the different boundaries surrounding the cusp. This paper presented multispacecraft observations of the magnetospheric cusps where much of the solar wind-magnetosphere interaction maps. The observations from the Cluster mission already provide new insights into the physics of the magnetosphere. It must be noted that the Cluster fleet inter-spacecraft distance will be enlarged up to $\sim 1 R_{\mathrm{E}}$ for the 2003 cusp period. Exploring the exterior cusp structure at large scale, which will also allow direct monitoring of the magnetosheath conditions, should soon give rise to interesting studies.

\section{Acknowledgements}

We are grateful to A. Barthe and E. Penou for their incomparable work in CIS data processing and visualization. This overview of Cluster observations in the cusp is a synthesis of the many topics discussed during the recent Cluster workshops. Many thanks to the Cluster community.

\section{References}

Angelopoulos, V., Mozer, F. S., Bonnell, J., Temerin, M., Somoza, M., Peterson, W. K., Collin, H. L., and Giles, B.: 2001. 'Wave Power Studies of Cusp Crossings with the Polar Satellite', J. Geophys. Res. 106, 5987.

Balogh, A., Carr, C. M., Acuña, M. H., Dunlop, M. W., Beek, T. J., Brown, P., Fornaçon, K.H., Georgescu, E., Glassmeier, K.-H., Harris, J., Musmann, G., Oddy, T., and Schwingenschuh, K.: 2001. 'The Cluster Magnetic Field Investigation: Overview of in-flight Performance and Initial Results', Ann. Geo. 19, 1207. 
Belmont, G., and Rézeau, L.: 2001. 'Magnetopause Reconnection Induced by Magnetosheath Hall-MHD Fluctuations', J. Geophys. Res. 106, 10751.

Bogdanova, R., Klecker, G., Paschmann, L. M., Kistler, C., Mouikis, E., Moebius, H., Reme, J. M., Bosqued, I., Dandouras, J. A., Sauvaud, N., Cornilleau-Wehrlin, H., Laakso, A., Korth, M. B., Bavassano-Cattaneo, T., Phan, C., Carlson, G., Parks, J. P., McFadden, M., McCarthy, R., and Lundin, R., 'Investigation of the source region of inospheric oxygen outflow in the cusp using multi-spacecraft observations by CIS onboard Cluster, Advances in Space Research' 2004 (accepted).

Bosqued, J. M., Phan, T. D., Dandouras, I., Escoubet, C. P., Réme, H., Balogh, A., Dunlop, M. W., Alcaydé, D., Amata, E., Bavassano-Cattaneo, M.-B., Bruno, R., Carlson, C., DiLellis, A. M., Eliasson, L., Formisano, V., Kistler, L. M., Klecker, B., Korth, A., Kucharek, H., Lundin, R., McCarthy, M., McFadden, J. P., Moebius, E., Parks, G. K., and Sauvaud, J.-A.: 2001. 'CLUSTER Observation of the High-Latitude Magnetopause and Cusp: First Results from the CIS Ion Instruments', Ann. Geophys. 19, 1545.

Cargill, P. J.: 1999. 'A Model for Plasma Flows and Shocks in the High-altitude Cusp', J. Geophys. Res. 104, 14647.

Carlson, C. W., and Torbert, R.: 1980. 'Solar Wind Ion Injections in the Morning Auroral Oval', J. Geophys. Res. 85, 2903.

Chang, S.-W., Scudder, J. D., Fennell, J. F., Friedl, R., Lepping, R. P., Russell, C. T., Trattner, K. J., Fuselier, S. A., Peterson, W. K., and Spence, H. E.: 2000. 'Energetic Magnetosheath Ions Connected to the Earth's Bow Shock: Possible Source of Cusp Energetic Ions', J. Geophys. Res. 105, 5471.

Chapman, S., and Ferraro, V. C.: 1931. 'A New Theory of Magnetic Storms', Terr. Magn. Atmosph. Elec. 36, 171.

Chen, J., and Fritz, T. A.: 2001. 'Energetic Oxygen Ions of Ionospheric Origin Observed in the Cusp', Geophys. Res. Lett. 28, 1459.

Décréau, P. M. E., Fergeau, P., Krasnoselskikh, V., Le Guirriec, E., Lévêque, M., Martin, Ph., Randriamboarison, O., Rauch, J. L., Sené, F. X., Séran, H. C., Trotignon, J. G., Canu, P., Cornilleau, N., de Féraudy, H., Alleyne, H., Yearby, K., Mögensen, P. B., Gustafsson, G., André, M., Gurnett, D. C., Darrouzet, F., Lemaire, J., Harvey, C. C., and Travnicek, P., Whisper experimenters.: 2001. 'Early Results from the Whisper Instrument on Cluster: An Overview', Ann. Geophys. 19, 1241.

Delcourt, D. C., and Sauvaud, J.-A.: 1998. 'Recirculation of Plasma Sheet Particles into the High-latitude Boundary Layer', J. Geophys. Res. 103, 26521.

Delcourt, D. C., and Sauvaud, J.-A.: 1999. 'Populating of the Cusp and Boundary Layers by Energetic (hundreds of keV) Equatorial Particles', J. Geophys. Res. 104, 22635.

Dubinin, E. et al.: 2002, "Polar - Interball Co-ordinated Observations of Plasma and Magnetic Field Characteristics in the Regions of the Northern and Southern Distant Cusps", J. Geophys. Res. 107, N A5, SMP 2.

Dungey, J. W.: 1961. 'Interplanetary Magnetic Field and the Auroral Zones', Phys. Rev. Lett. 6, 47 .

Dunlop, M. W., Woodward, T. I., Southwood, D. J., Glassmeier, K.-H., and Elphic, R. C.: 1997. 'Merging 4 Spacecraft Data: Concepts used for Analysing Discontinuities', $A d v$. Space Res. 20, 1101.

Escoubet, C. P., Smith, M. F., Fung, S. F., Anderson, P. C., Hoffman, R. A., Basinska, E. M., and Bosqued, J.-M.: 1992, "Staircase Ion Signature in the Polar Cusp - A Case Study", Geophys. Res. Lett. 19, 1735.

Fedorov, A., Dubinin, E., Song, P., Budnick, E., Larson, P., and Sauvaud, J. A.: 2000. 'Characteristics of the Exterior Cusp for Steady Southward Interplanetary Magnetic Field: Interball Observations', J. Geophys. Res. 105, 15945. 
Frank, L. A.: 1971. 'Plasma in the Earth"s Polar Magnetosphere', J. Geophys. Res. 76, 5202.

Fritz, T. A., Chen , J., and Siscoe, G. L.: 2003, "Energetic Ions, Large Diamagnetic Cavities, and Chapman-Ferraro Cusp", J. Geophys. Res. 108, SMP 17.

Fuselier, S. A., Trattner, K. J., and Petrinec, S. M.: 2000. 'Cusp Observations of High and Low-laltitude Reconnection for Northward IMF', J. Geophys. Res. 105, 27509.

Haerendel, G.: 1978. 'Microscopic Plasma Processes Related to Reconnection', J. Atmos. Terr. Phys. 40, 343.

Haerendel, G., Paschmann, G., Sckopke, N., Rosenbauer, H., and Hedgecock, P. C.: 1978. 'The Frontside Boundary Layer of the Magnetosphere and the Problem of Reconnection', J. Geophys. Res. 83, 3195.

Harvey, C. C.: 1998, "Spatial Gradients and the Volumetric Tensor, Analysis Methods for Multi-spacecraft Data”, Int. Space Sci. Inst. Scientific Report Book, 307.

Heikkila, W. J., and Winningham, J. D.: 1971. 'Penetration of Magnetosheath Plasma to Low Altitudes through the Dayside Magnetospheric Cusps', J. Geophys. Res. 76, 883.

Kremser, G., Woch, J., Mursula, K., Tanskanen, P., Wilken, B., and Lundin, R.: 1995. 'Origin of Energetic Ions in the Polar Cusp Inferred from Ion Composition MeasuRèments by the Viking satellite', Ann. Geophys. 13, 595.

Kuznetsova, M. M. and Zelenyi, L. M.: 1990, "The Theory of FTE : Stochastic Percolation Model”, in C. T. Russell, E. R. Priest, and L. C. Lee (eds.), Physics of Magnetic Flux Ropes, AGU.

Lavraud, B., Dunlop, M. W., Phan, T. D., Réme, H., Bosqued, J.-M., Dandouras, I., Sauvaud, J.-A., Lundin, R., Taylor, M. G. G. T., Cargill, P. J., Mazelle, C., Escoubet, C. P., Carlson, C. W., McFadden, J. P., Parks, G. K., Moebius, E., Kistler, L. M., Bavassano-Cattaneo, M.-B., Korth, A., Klecker, B., and Balogh A.: 2002, "Cluster Observations of the Exterior Cusp and its Surrounding Boundaries Under Northward IMF", Geophys. Res. Lett. 29, N. 20, 56.

Le, G., Blanco-Cano, X., Russell, C. T., Zhou, X.-W., Mozer, F., Trattner, K. J., Fuselier, S. A., and Anderson, B. J.: 2001. 'Electromagnetic Ion Cyclotron Waves in the High Altitude Cusp: Polar Observations', J. Geophys. Res. 106, 19067.

Lemaire, J., and Roth, M.: 1978. 'Penetration of Solar Wind Plasma Elements into the Magnetosphere', J. Atmos. Terr. Phys. 40, 331.

Lockwood, M., and Davis, C. J.: 1995. 'Occurrence probability, width and number of step of cusp precipitation for fully pulsed reconnection at the dayside magnetopause', J. Geophys. Res. 100, 7627.

Lockwood, M., and Smith, M. F.: 1992. 'The Variation of Reconnection Rate at the Dayside Magnetopause and Cusp Ion Precipitation', J. Geophys. Res. 97, 14841.

Lockwood, M., Opgenoorth, H., van Eyken, A. P., Fazakerley, A., Bosqued, J.-M., Denig, W., Wild, J. A., Cully, C., Greenwald, R., Lu, G., Amm, O., Frey, H., Strømme, A., Prikryl, P., Hapgood, M. A., Wild, M. N., Stamper, R., Taylor, M., McCrea, I., Kauristie, K., Pulkkinen, T., Pitout, F., Balogh, A., Dunlop, M., Réme, H., Behlke, R., Hansen, T., Provan, G., Eglitis, P., Morley, S. K., Alcaydé, D., Blelly, P.-L., Moen, J., Donovan, E., Engebretson, M., Lester, M., Watermann, J., and Marcucci, M. F.: 2001a. 'Coordinated Cluster, Ground-based Instrumentation and Low-altitude Satellite Observations of Transient Poleward-moving Events in the Ionosphere and in the Tail Lobe', Ann. Geophys. 19, 1589.

Lockwood, M., Fazakerley, A., Opgenoorth, H., Moen, J., van Eyken, A. P., Dunlop, M., Bosqued, J.-M., Lu, G., Cully, C., Eglitis, P., McCrea, I. W., Hapgood, M. A., Wild, M. N., Stamper, R., Denig, W., Taylor, M., Wild, J. A., Provan, G., Amm, O., Kauristie, K., Pulkkinen, T., Strømme, A., Prikryl, P., Pitout, F., Balogh, A., Réme, H., Behlke, R., 
Hansen, T., Greenwald, R., Frey, H., Morley, S. K., Alcaydé, D., Blelly, P.-L., Donovan, E., Engebretson, M., Lester, M., Watermann, J.., and Marcucci, M. F.: 2001b. 'Coordinated Cluster and Ground-based Instrument Observations of Transient Changes in the Magnetopause Boundary Layer during an Interval of Predominantly Northward IMF: Relation to Reconnection Pulses and FTE Signatures', Ann. Geophys. 19, 1613.

Lui, A. T. Y.: 2001. 'Current Controversies in Magnetospheric Physics', Rev. Geophys. 39, 535. Lundin, R., and Dubinin, E.: 1985. 'Solar Wind Energy Transfer Regions Inside the Dayside Magnetopause - II: Accelerated Heavy Ions as Tracers for MHD Processes in the Dayside Boundary Layer', Planet. Space Sci. 33, 891.

Lundin, R., Sauvaud, J.-A., Réme, H., Balogh, A., Dandouras, I., Bosqued, J. M., Carlson, C., Parks, G. K., Moebius, E., Kistler, L. M., Klecker, B., Amata, E., Formisano, V., Dunlop, M. W., Eliasson, L., Korth, A., Lavraud, B.., and McCarthy, M.: 2003. 'Evidence for Impulsive Solar Wind Plasma Penetration through the Dayside Magnetopause', Ann. Geophys. 21, 457.

Merka, J., Safrankova, J., Nemecek Z., et al.: 2000, "High-altitude Cusp: INTERBALL Observations", Adv. Space Res. 25, No. 7/8, 1425.

Newell, P. T., and Meng, C. I.: 1988. 'The Cusp and the Cleft/LLBL: Low Altitude Identification and Statistical Local Time Variation', J. Geophys. Res. 93, 14549.

Newell, P. T., Meng, C. I., Sibeck, D. G., and Lepping, P.: 1989. 'Some Low-altitude Cusp Dependencies on the Interplanetary Magnetic Field', J. Geophys. Res. 94, 8921.

Newell, P. T., and Meng, C. I.: 1991. 'Ion Acceleration at the Equatorward Edge of the Cusp: Low Altitude Observations of Patchy Merging', Geophys. Res. Lett 18, 1829.

Newell, P. T., and Meng, C. I.: 1994. 'Ionospheric Projections of Magnetospheric Regions under Low and High Solar Wind Pressure Conditions', J. Geophys. Res. 99, 273.

Ohtani, S., Potemra, T. A., Newell, P. T., Zanetti, L. J., Iijima, T., Watanabe, M., Blomberg, L. G., Elphinstone, R. D., Murphree, J. S., Yamauchi, M., and Woch, J.: 1995. 'Four Large-scale Field-aligned Current Systems in the Dayside High-latitude Region', J. Geophys. Res. 100, 137-153.

Onsager, T. G., scudder, J. D., Lockwood, M., and Russell, C. T.: 2001. 'Reconnection at the High Latitude Magnetopause during Northward Interplanetary Magnetic Field Conditions', J. Geophys. Res. 106, 25467.

Paschmann, G., Haerendel, G., Sckopke, N., Rosenbauer, H.., and Hedgecock, P. C.: 1976. 'Plasma and Magnetic Field Characteristics of the Distant Polar Cusp Near Local Noon: The Entry Layer', J. Geophys. Res. 81, 2883.

Pickett, J. S., Franz, J. R., Scudder, J. D., Menietti, J. D., Gurnett, D. A., Hospodarsky, G. B., Braunger, R. M., Kintner, P. M., and Kurth, W. S.: 2001. 'Plasma Waves Observed in the Cusp Turbulent Boundary Layer: An Analysis of High Time Resolution Wave and Particle MeasuRèments from the Polar Spacecraft', J. Geophys. Res. 106, 19081.

Reiff, P. H., Hill, T. W., and Burch, J. L.: 1977. 'Solar Wind Plasma Injection at the Dayside Magnetospheric Cusp', J. Geophys. Res. 82, 479.

Réme, H., Aoustin, C., Bosqued, J. M., Dandouras, I., Lavraud, B., Sauvaud, J.-A., Barthe, A., Bouyssou, J., Camus, Th., Cur-Joly, O., Cros, A., Cuvilo, J., Ducay, F., Garbarowitz, Y., Médale, J. L., Penou, E., Perrier, H., Romefort, D., Rouzaud, J., Vallat, C., Alcaydé, D., Jacquey, C., Mazelle, C., and d'Uston, C., : 2001. 'First Multispacecraft Ion MeasuRèments in and Near the Earth's Magnetosphere with the Identical CLUSTER Ion Spectrometry (CIS) Experiment', Ann. Geophys. 19, 1303.

Roth, M.: 1992. 'On Impulsive Penetration of Solar Wind Plasmoids into the Geomagnetic Field', Planet. Space Sci. 40, 193.

Russell, C. T., and Elphic, R. C.: 1978. 'Initial ISEE Magnetometer Results - Magnetopause Observations', Space Sci. Rev. 22, 681-715. 
Russell, C. T.: 2000. 'POLAR Eyes the Cusp, Proc. of the Cluster II Workshop: Multiscale/ Multipoint Plasma Measurèments', ESA SP-449, 47.

Russell, C. T., Le, G., and Petrinec, S. M.: 2000. 'Cusp Observations of High and Low Latitude Reconnection under Northward IMF: and Alternate View', J. Geophys. Res. 105, 5489.

Sauvaud, J.-A., Lundin, R., Réme, H., McFadden, J. P., Carlson, C., Parks, G. K., Moebius, E., Kistler, L. M., Klecker, B., Amata, E., DiLellis, A. M., Formisano, V., Bosqued, J. M., Dandouras, I., Décréau, P., Dunlop, M. W., Eliasson, L., Korth, A., Lavraud, B.., and McCarthy, M.: 2001. 'Intermittent Thermal Plasma Acceleration Linked to Sporadic Motions of the Magnetopause, First Cluster Results', Ann. Geophys. 19, 1523.

Savin, S. P., : 1998. 'The Cusp/magnetosheath Interface on May 29, 1996 : Interball 1 and Polar Observations', Geophys. Res. Lett. 25, 2963.

Sckopke, N., Paschmann, G., Rosenbauer, H., and Fairfield, D. H.: 1976. 'Influence of the Interplanetary Magnetic Field on the Occurrence and Thickness of the Plasma Mantle', $J$. Geophys. Res. 81, 2687-2691.

Sibeck, D. G., Paschmann, G., Treumann, R. A., Fuselier, S. A., Lennartsson, W., Lockwood, M., Lundin, R., Ogilvie, K. W., Onsager, T. G., and Phan, T. D., : 1999. 'Chapter 5-Plasma Transfer Processes at the Magnetopause', Space Sci. Rev. 88, 207.

Song, P., Russell, C. T., and Thomsen, M. F.: 1992. 'Slow Mode Transition in the Front Side Magnetosheath', J. Geophys. Res. 97, 8295.

Sonnerup, B. U. O., and Cahill, L. J.: 1967. 'Magnetopause Structure and Attitude from Explorer 12 Observations', J. Geophys. Res. 72, 171.

Stenuit, H., Sauvaud, J.-A., Delcourt, D. C., Mukai, T., Kokubun, S., Fujimoto, M., Buzulukova, N. Y., Kovrazhkin, R. A., Lin, R. P., and Lepping, R. P.: 2001. 'A Study of Ion Injections at the Dawn and Dusk Polar Edges of the Auroral Oval', J. Geophys. Res. 106, 29619.

Taylor, M. G. G. T. and Cargill, P. J.: 2001, “A Agnetohydrodynamic Model of Plasma Flow in the High Altitude Cusp", J. Geophys. Res. 107, N. A6, SMP 13.

Trattner, K. J., Fuselier, S. A., Peterson, W. K., Sauvaud, J. A., Stenuit, H., Dubouloz, N., and Kovrazhkin, R. A.: 1999. 'On Spatial and Temporal Structures in the Cusp', J. Geophys. Res. 104, 28411.

Trattner, K. J., Fuselier, S. A., Peterson, W. K., Chang, S.-W., Friedel, R., and Aellig, M. R.: 2001. 'Origins of Energetic Ions in the Cusp', J. Geophys. Res. 106, 5967.

Tsyganenko, N. A.: 1989. 'A Magnetospheric Magnetic Field Model with a Warped Tail Current Sheet', Planet. Space Sci. 37, 5.

Vasyliunas, V. M., Skopke, N., and Rosenbauer, H.: 1977. 'Structure of the Polar Magnetosheath as Observed by HEOS 2', EOS Transac. AGU 58, 1206.

Vasyliunas, V. M.: 1995. 'Multi-branch Model of the Open Magnetopause', Geophys. Res. Lett. 22, 1245.

Vontrat-Reberac, A., Bosqued, J. M., Taylor, M. G., Lavraud, B., Fontaine, D., Dunlop, M. W., Laakso, H., Cornilleau-Werhlin, N., Canu, P. and Fazarkerley, A.: 2003, "Cluster Observations of the High-Altitude Cusp for Northward Interplanetary Magnetic Field: A Case Study", J. Geophys. Res. accepted.

Walters, G. K.: 1966. 'On the Existence of a Second Standing Shock Wave Attached to the Magnetosphere', J. Geophys. Res. 71, 1341.

Whalthour, D. W., Sonnerup, B. U. O., and Russell, C. T.: 1995. 'Observation of a Slow-mode Shock in the Dayside Magnetopause Reconnection Layer', Adv. Space Res. 15, 501.

Woch, J., and Lundin, R.: 1992. 'Magnetosheath Plasma Precipitation in the Polar Cusp and its Control by the Interplanetary Magnetic Field', J. Geophys. Res. 97, 1421. 
Yamauchi, M., and Lundin, R.: 1994. 'Classification of Large-scale and Meso-scale Ion Dispersion Patterns Observed by Viking over the Cusp-mantle Region', in J. A. Holtet, and A.. Egeland (eds.), Physical Signatures of Magnetospheric Boundary Layer Process, Kluwer Academic Publishers, Dordrecht Netherlands, pp. 99-109.

Yamauchi, M., Nilsson, H., Eliasson, L., Norberg, O., Boehm, M., Clemmons, J. H., Lepping, R. P., Blomberg, L., Ohtani, S.-I., Yamamoto, T., Mukai, T., Terasawa, T., and Kokubun, S.: 1996. 'Dynamic Response of the Cusp Morphology to the Solar Wind: A Case Study during Passage of the Solar Wind Plasma Cloud on February 21, 1994', J. Geophys. Res. 101, 24675-24687.

Yamauchi, M., and Lundin, R.: 1997. 'The Wave-assisted Cusp Model: Comparison to Lowaltitude Observations', Phys. Chem. Earth 22, 729-734. 